\title{
Impact of black carbon aerosol over Italian basin valleys: high-resolution measurements along vertical profiles, radiative forcing and heating rate
}

\author{
L. Ferrero ${ }^{1}$, M. Castelli ${ }^{2,7}$, B. S. Ferrini ${ }^{1}$, M. Moscatelli ${ }^{1}$, M. G. Perrone ${ }^{1}$, G. Sangiorgi ${ }^{1}$, L. D'Angelo ${ }^{1}$, G. Rovelli ${ }^{1}$, \\ B. Moroni ${ }^{3,6}$, F. Scardazza ${ }^{3}$, G. Močnik ${ }^{4}$, E. Bolzacchini ${ }^{1}$, M. Petitta ${ }^{2}$, and D. Cappelletti ${ }^{5,6}$ \\ ${ }^{1}$ POLARIS Research Centre, Department of Earth and Environmental Sciences, University of Milano-Bicocca, \\ Piazza della Scienza 1, 20126, Milan, Italy \\ ${ }^{2}$ EURAC Institute for Applied Remote Sensing, Viale Druso 1, 39100, Bolzano, Italy \\ ${ }^{3}$ DICA, Università degli Studi di Perugia, Via G. Duranti 93, 06125 Perugia, Italy \\ ${ }^{4}$ Aerosol d.o.o., Kamniška 41, 1000 Ljubljana, Slovenia \\ ${ }^{5}$ Dipartimento di Chimica, Biologia e Biotecnologie, Università degli Studi di Perugia, Via Elce di Sotto 8, \\ 06123 Perugia, Italy \\ ${ }^{6}$ SMAArt, Università degli Studi di Perugia, Piazza dell’Università 1, 06100 Perugia, Italy \\ ${ }^{7}$ Dipartimento di Ingegneria Civile, Ambientale e Meccanica, Università di Trento, via Mesiano 77, 38123 Trento, Italy
}

Correspondence to: L. Ferrero (luca.ferrero@unimib.it)

Received: 4 December 2013 - Published in Atmos. Chem. Phys. Discuss.: 9 January 2014

Revised: 31 July 2014 - Accepted: 15 August 2014 - Published: 16 September 2014

\begin{abstract}
A systematic study of black carbon (BC) vertical profiles measured at high-resolution over three Italian basin valleys (Terni Valley, Po Valley and Passiria Valley) is presented. BC vertical profiles are scarcely available in literature. The campaign lasted 45 days and resulted in 120 measured vertical profiles. Besides the $\mathrm{BC}$ mass concentration, measurements along the vertical profiles also included aerosol size distributions in the optical particle counter range, chemical analysis of filter samples and a full set of meteorological parameters. Using the collected experimental data, we performed calculations of aerosol optical properties along the vertical profiles. The results, validated with AERONET data, were used as inputs to a radiative transfer model (libRadtran). The latter allowed an estimation of vertical profiles of the aerosol direct radiative effect, the atmospheric absorption and the heating rate in the lower troposphere.

The present measurements revealed some common behaviors over the studied basin valleys. Specifically, at the mixing height, marked concentration drops of both $\mathrm{BC}$ (range: from $-48.4 \pm 5.3$ to $-69.1 \pm 5.5 \%$ ) and aerosols (range: from $-23.9 \pm 4.3$ to $-46.5 \pm 7.3 \%$ ) were found. The measured percentage decrease of $\mathrm{BC}$ was higher than that of aerosols:
\end{abstract}

therefore, the BC aerosol fraction decreased upwards. Correspondingly, both the absorption and scattering coefficients decreased strongly across the mixing layer (range: from $-47.6 \pm 2.5$ to $-71.3 \pm 3.0 \%$ and from $-23.5 \pm 0.8$ to $-61.2 \pm 3.1 \%$, respectively) resulting in a single-scattering albedo increase along height (range: from $+4.9 \pm 2.2$ to $+7.4 \pm 1.0 \%$ ).

This behavior influenced the vertical distribution of the aerosol direct radiative effect and of the heating rate. In this respect, the highest atmospheric absorption of radiation was predicted below the mixing height $(\sim 2-3$ times larger than above it) resulting in a heating rate characterized by a vertical negative gradient (range: from $-2.6 \pm 0.2$ to $-8.3 \pm 1.2 \mathrm{~K} \mathrm{day}^{-1} \mathrm{~km}^{-1}$ ). In conclusion, the present results suggest that the $\mathrm{BC}$ below the mixing height has the potential to promote a negative feedback on the atmospheric stability over basin valleys, weakening the ground-based thermal inversions and increasing the dispersal conditions. 


\section{Introduction}

Atmospheric aerosols influence the Earth's climate through direct effects (sunlight absorption and scattering), indirect effects (i.e., modifying the lifetime of the clouds) and semidirect effects (i.e., affecting the thermal structure of the atmosphere) (Ramanathan and Feng, 2009; Koren et al., 2008, 2004; IPCC, 2013; Kaufman et al., 2002). The instantaneous direct radiative effect (DRE) due to the aerosol load amount to $\sim-10$ to $20 \mathrm{~W} \mathrm{~m}^{-2}$ at the top of atmosphere (TOA) and can reach $\sim-50 \mathrm{~W} \mathrm{~m}^{-2}$ at the surface (Perrone and Bergamo, 2011).

Among the various aerosol constituents, black carbon (BC) is the second most important anthropogenic climateforcing agent (Ramanathan and Carmichael, 2008; Bond et al., 2013). The averaged BC-DRE at the TOA ranges between +0.08 and $+1.4 \mathrm{~W} \mathrm{~m}^{-2}$ (Samset et al., 2013; Ramanathan and Carmichael, 2008; Jacobson, 2001) with a best estimate of $+0.71 \mathrm{~W} \mathrm{~m}^{-2}$ (Bond et al., 2013). Unlike $\mathrm{CO}_{2}$, which is distributed quite homogeneously in the atmosphere, BC affects the climate with significant spatial variation and the magnitude of the $\mathrm{BC}$ radiative forcing are also highly uncertain; therefore, $\mathrm{BC}$ may affect the climate by both warming the atmosphere (in average $+2.6 \mathrm{~W} \mathrm{~m}^{-2}$ and instantaneously up to $+75 \mathrm{~W} \mathrm{~m}^{-2}$ ) or cooling (masking) the surface (in average $-1.7 \mathrm{~W} \mathrm{~m}^{-2}$ and instantaneously down to $-60 \mathrm{~W} \mathrm{~m}^{-2}$ ) (Chakrabarty et al., 2012; Ramanathan and Carmichael, 2008).

The wide range of reported BC-DRE values, reported in literature, is due to different reasons: the complexity of aerosol chemistry (i.e., mixing state) (Ramana et al., 2010), the surface albedo (Seinfeld and Pandis, 1998) and, most important, the spatial heterogeneity of BC concentrations (horizontal and vertical) due to its relatively short lifetime (weeks) when compared to $\mathrm{CO}_{2}$ (Samset et al., 2013; Cape et al., 2012). In particular, recent modeling of the BC-DRE (Samset et al., 2013; Zarzycki and Bond, 2010) evidenced opposing DRE behaviors depending on the $\mathrm{BC}$ abundance along the vertical profile. The resulting overall degree of uncertainty attributable to the assumptions about the vertical distribution of $\mathrm{BC}$ was estimated to be in the range $20-50 \%$.

This is very important as the vertical heterogeneity of $\mathrm{BC}$, and therefore of its DRE, the thermal structure of the atmosphere; in particular, heating rates may vary as a function of height in a range from 0.5 to $2 \mathrm{~K} \mathrm{day}^{-1}$ (Chakrabarty et al., 2012; Ramana et al., 2010; Tripathi et al., 2007). As a result, different kinds of feedback can take place, such as those on clouds dynamics (Bond et al., 2013), on regional circulation systems (i.e., monsoons) and on the planetary boundary layer dynamics (Ramanathan and Feng, 2009; Ramanathan and Carmichael, 2008).

Since it is likely that different regions have a different sensitivity to all of these processes (Bond et al., 2013) and since modeling based on observational constraints of the $\mathrm{BC}$ vertical distribution are particularly poor, there is the need to measure the $\mathrm{BC}$ vertical distribution on a regional scale: from areas characterized by anthropogenic emissions at ground to areas characterized by long-range transport phenomena (Corrigan et al., 2008; Ramana et al., 2007), where most of the uncertainty on the BC-DRE comes from the region above $5 \mathrm{~km}$ (Samset et al., 2013). It is clear that the BC evolution in the first hundred meters above the planet surface, especially across the mixing layer, is going to strongly affect the BC concentration in the upward atmospheric layers. In this respect, measurements in the planetary boundary layer are important and can be conducted by tethered balloons and unmanned aerial vehicles (Ferrero et al., 2012; Corrigan et al., 2008; Maletto et al., 2003). However, up till now, $\mathrm{BC}$ profiles were globally scarce compared to groundlevel data, even if recently many measurements have been reported over the Asian region (Safai et al., 2012; Babu et al., 2011; Ramana et al., 2010; Corrigan et al., 2008; Tripathi et al., 2007) and some over the ocean (Schwarz et al., 2013, 2010). Conversely, there is a noticeable lack of BC profile measurements over Europe, where reported campaigns were limited in time and/or in space (McMeeking et al., 2010; Schwarz et al., 2006); even in Italy, the only measured vertical profiles of $\mathrm{BC}$ and absorption coefficient are reported for a short campaign by Ferrero et al. (2011a).

Thus, there is a clear need to improve the knowledge about aerosol vertical profiles over Europe. This is true especially over mountainous regions. The complex morphological structure of the Italian landscape represents an interesting and significant case study for BC and aerosols monitoring. The Italian territory is characterized by a multitude of basin valleys surrounded by hills or mountains, where urban and industrial centers are usually settled. These valleys represent areas where low wind speeds and conditions of atmospheric stability are common, thus promoting the formation of strong vertical aerosol (and BC) gradients in the lower troposphere (Moroni et al., 2012, 2013; Ferrero et al., 2011a; Carbone et al., 2010; Rodríguez et al., 2007).

This paper tries to fill a gap in measurement of vertical profiles. We report a comparative study of $\mathrm{BC}$ and aerosol vertical profiles measured over three different Italian basin valleys (Terni Valley in the central Apennines; Po Valley in northern Italy; Passiria-Val Venosta valleys in the Alps). An extensive field campaign allowed collecting data for 120 vertical profiles in less than 45 days. A calculation of DRE and heating-rates profiles has been implemented, starting from the experimental data. Finally, a modeling of possible feedbacks induced by $\mathrm{BC}$ gradients in the lower troposphere in relationship to the mixing height $(\mathrm{MH})$ dynamics has been performed.

In the next sections, we briefly describe the sampling sites (Sect. 2.1) and the vertical profile measurements (Sect. 2.2). $\mathrm{BC}$ and aerosol chemistry determination are explained in Sects. 2.2.1 and 2.2.2. The optical particle counter sizedistribution correction and the optical properties calculation using the Mie theory are described in Sect. 2.3 and the 
radiative transfer in Sect. 2.4. Results and discussion follow in Sect. 3, with the conclusions in the final Sect. 4.

\section{Experimental}

\subsection{Sampling sites}

Balloon soundings were carried out during winter 2010 over three Italian basin valleys in the following sites (Fig. 1a):

1. Terni (TR; $42^{\circ} 33^{\prime} 58^{\prime \prime} \mathrm{N}, 12^{\circ} 38^{\prime} 56^{\prime \prime} \mathrm{E}$; $122 \mathrm{~m}$ a.s.l.), located in the Terni Valley in central Italy. The Terni Valley $\left(\sim 50 \mathrm{~km}^{2}\right)$ is surrounded by mountains on three sides (NNE, SE and SW) and hosts the medium-sized town of Terni, with the largest stainless-steel production site in Europe and various other industries. In wintertime, wind speed is low and the aerosol dispersion is limited with height. A full description of the site concerning the aerosol properties (chemistry, sources and vertical profiles) is reported in Moroni et al. (2012, 2013) and Ferrero et al. (2012). Within the present work, vertical aerosol and $\mathrm{BC}$ profiles were measured over Terni from 27 January to 4 February for a total of 40 profiles.

2. Milan (MI; $45^{\circ} 31^{\prime} 19^{\prime \prime} \mathrm{N}, 9^{\circ} 12^{\prime} 46^{\prime \prime} \mathrm{E} ; 136 \mathrm{~m}$ a.s.l.), located in the Po Valley $\left(\sim 46000 \mathrm{~km}^{2}\right.$, northern Italy) in the midst of an extensive conurbation that is one of the most industrialized and heavily populated areas in Europe. In the Po Valley stagnant conditions often occur causing a marked seasonal variation of aerosol concentrations within the mixing layer. Balloon soundings were conducted at the Torre Sarca sampling site within the Milano Bicocca University Campus in the northern side of Milan (the site is active from 2005 for aerosol characterization both at ground level and along vertical profiles). A full description of the site and the related aerosol properties (vertical profiles, chemistry, sources and toxicity) are reported in Ferrero et al. (2010), in Perrone et al. (2013) and in Sangiorgi et al. (2011). Within the framework of the 2010 winter campaign, vertical aerosol and BC profiles were measured over Milan from 12 to 25 February for a total of 36 profiles.

3. Merano (ME; $46^{\circ} 38^{\prime} 52^{\prime \prime} \mathrm{N}, 11^{\circ} 10^{\prime} 13^{\prime \prime} \mathrm{E} ; 272 \mathrm{~m}$ a.s.l.), located at the intersection of two main Alpine valleys: Val Venosta (E-W orientation) and Val Passiria (N-S orientation) allowing the air masses to be transported both from continental Europe (north) and from the Po Valley (south). The sampling site was located in a rural area at the location of the local authority background station for air quality monitoring of the local authorities (Merano 2 station, APPA). A full description of the site and aerosol pollution in the surrounding valleys are reported in Emili et al. (2010). Within the 2010 winter
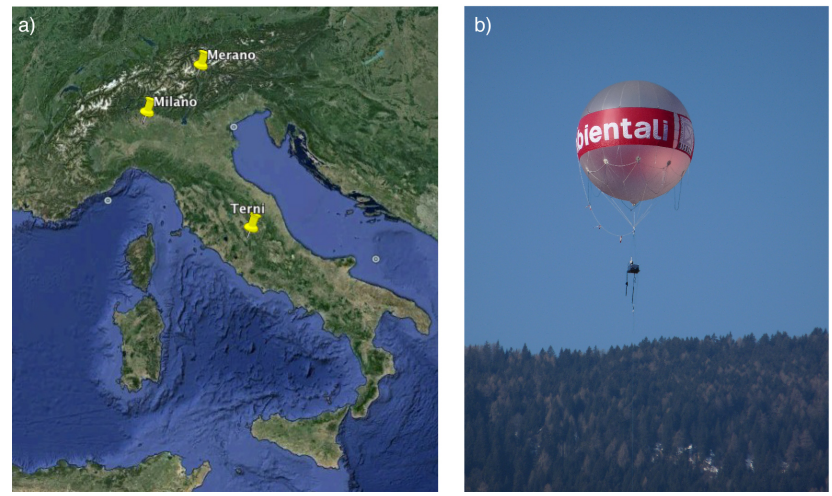

Figure 1. (a) Location of the three sampling sites: Terni in central Italy (Terni Valley), Milan in northern Italy (Po Valley) and Merano in the Alpine region (between Passiria and Val Venosta valleys); (b) the tethered balloon flying over Merano with the instrumentation package.

campaign, vertical aerosol and $\mathrm{BC}$ profiles were measured over Merano from 3 to 13 March for a total of 40 profiles.

\subsection{Vertical profile measurements}

Vertical BC and aerosol profile measurements were carried out over TR, MI and ME by means of a helium-filled tethered balloon (diameter $4.5 \mathrm{~m}$; volume $47.8 \mathrm{~m}^{3}$; payload $40 \mathrm{~kg}$; Fig. 1b) equipped with an instrumental package consisting of (1) the micro-Aethalometer microAeth ${ }^{\circledR}$ AE51 (Magee Scientific) to measure the $\mathrm{BC}$ concentrations and the absorption coefficient at $880 \mathrm{~nm}$; (2) an optical particle counter (OPC, 1.107 Environcheck Grimm, 31 class-sizes ranging from 0.25 to $32 \mu \mathrm{m}$ ) for the particle number-size distribution determination; (3) a portable cascade impactor (Sioutas equipped with Leland Legacy pump, SKC) to collect $\mathrm{PM}_{2.5}$ samples at different heights (Sect. 2.2.2) and (4) a meteorological station (LSI-Lastem: pressure, temperature and relative humidity).

An electric winch controlled the balloon ascent/descent rate which was set at $30.0 \pm 0.1 \mathrm{~m} \mathrm{~min}^{-1}$; a measurement time resolution of $6 \mathrm{~s}$ was chosen for each instrument, giving $3.0 \mathrm{~m}$ of measurement vertical resolution. The maximum height reached during each flight depended on atmospheric conditions and the location; for the majority of profiles, the maximum height was between 600 and $800 \mathrm{~m}$ a.g.l.

Vertical aerosol profiles allowed the determination of the MH by means of a gradient method, as aerosols act as tracer of atmospheric plumes integrating the effects of turbulent forces (thermal and mechanical) along height; the gradient method's ability to infer the MH has yet been assessed in previous works (Ferrero et al., 2010, 2011a, b). The MH will be used to calculate averaged aerosol and $\mathrm{BC}$ profiles for each site (Sect. 3.2) 


\subsubsection{Aethalometer data: black carbon and the related absorption coefficient}

$\mathrm{BC}$ and absorption coefficient profiles have been determined using the microAeth ${ }^{\circledR}$ AE51 (Magee Scientific, $250 \mathrm{~g}$, $\left.117 \times 66 \times 38 \mathrm{~mm}^{3}\right)$. The sample is continuously deposited on the filter and the AE51 measures light attenuation (ATN) at $880 \mathrm{~nm}$ induced by BC collected on the PTFE-coated borosilicate glass fiber filter (Fiberfilm ${ }^{\text {TM }}$ Filters, Pall Corporation) relative to a clean part of the filter. ATN is calculated as

$\mathrm{ATN}=100 \cdot \ln \left(I_{0} / I\right)$,

where $I_{0}$ and $I$ are the light intensities transmitted throughout a reference blank spot and the aerosol-laden $3 \mathrm{~mm}$ diameter sample spot of the filter, respectively.

The attenuation coefficient of the filtered aerosol particles, $b_{\mathrm{ATN}}$, is derived from ATN as follows (Weingartner et al., 2003):

$b_{\mathrm{ATN}}=\frac{A}{100 Q} \frac{\Delta \mathrm{ATN}}{\Delta t}$,

where $\triangle$ ATN indicates the ATN variation during the time period $\Delta t, A$ is the sample spot area $\left(7.1 \times 10^{-6} \mathrm{~m}^{2}\right)$ and $Q$ is the volumetric flow rate $\left(2.5 \times 10^{-6} \mathrm{~m}^{3} \mathrm{~s}^{-1}\right)$. The aerosol absorption coefficient, $b_{\mathrm{abs}}$, is calculated as follows:

$b_{\mathrm{abs}}=\frac{b_{\mathrm{ATN}}}{C \cdot R(\mathrm{ATN})}$,

where $C$ and $R(\mathrm{ATN})$ are the multiple scattering optical enhancement factor and the aerosol loading factor, respectively. Briefly, the constant optical enhancement factor $C$ compensates for the enhanced optical path through the filter caused by multiple scattering induced by the filter fibers themselves (Schmid et al., 2006; Arnott et al., 2005; Weingartner et al., 2003). For the AE51 microAeth ${ }^{\circledR}$ the parameter $C$ is $2.05 \pm 0.03$ (at $\lambda=880 \mathrm{~nm}$ ) (Ferrero et al., 2011a). The parameter $R(\mathrm{ATN})$ compensates for the nonlinearity - the loading effect due to reduction of the measurement sensitivity due to the saturation caused by the collected sample on the filter. The compensation with the parameter $R(\mathrm{ATN})$ is needed only when ATN becomes higher than 20 (Schmid et al., 2006; Arnott et al., 2005; Weingartner et al., 2003). In this study, the experimental design allows us to neglect the use of $R(\mathrm{ATN})$ : all $\mathrm{BC}$ vertical profiles were conducted by changing the filter ticket between profiles, thus resulting in ATN always lower than 20 as recommended by Weingartner et al. (2003). It is necessary to underline that, to rightly estimate DRE profiles, multiple-wavelength optical properties are needed (Sect. 2.4); thus the $b_{\text {abs }}$ derived from the microAeth ${ }^{\circledR}$ AE51 at $880 \mathrm{~nm}$ was used in this study during the validation of the optical properties calculation to verify their correct shaping in order to avoid the presence of compensatory effects along profiles (Sects. 2.3 and 3.2.1).
Finally, to determine the $\mathrm{BC}$ ambient concentration the apparent mass attenuation cross section $\left(\sigma_{\mathrm{ATN}}=12.5 \mathrm{~m}^{2} \mathrm{~g}^{-1}\right)$ is needed; it is defined for the BC collected on the PTFEcoated borosilicate glass fiber filter and is provided by the manufacturer. The $\mathrm{BC}$ concentrations are determined as follows:

$\mathrm{BC}=\frac{b_{\mathrm{ATN}}}{\sigma_{\mathrm{ATN}}}$.

\subsubsection{Aerosol chemistry determination}

The knowledge of aerosol chemical composition along height is fundamental to calculate the aerosol refractive index along vertical profiles (Sect. 2.3.1), which is the basis for the correction of the OPC size distribution (Sect. 2.3.2), for the determination of aerosol optical properties and DRE calculations (Sects. 2.3, 2.4, 3.2 and 3.3).

BC concentrations were measured with a microAethalometer, as reported in the previous section (Sect. 2.2.1). Moreover, at ME site only, a 7- $\lambda$ Aethalometer (AE31, Magee Scientific) was also present at ground level, and recorded ground $\mathrm{BC}$ concentrations continuously during the campaign.

In order to complete the aerosol chemistry along profiles, $\mathrm{PM}_{2.5}$ samples were collected during balloon flights at two different heights: ground level (below the mixing height: $\mathrm{BMH}$ ), and above the mixing height (AMH: $\sim 600 \mathrm{~m}$ a.g.l., depending on the local atmospheric conditions).

$\mathrm{PM}_{2.5}$ at ground level was sampled using the TECORA ECHO-PM gravimetric system $\left(\mathrm{PM}_{2.5}\right.$ sampling head, flow $2.3 \mathrm{~m}^{3} \mathrm{~h}^{-1}$; STERLITECH Polycarbonate filters, $\varnothing=47 \mathrm{~mm}$ ), while at higher altitudes it was sampled using a balloon-borne portable cascade impactor (Sioutas type with Leland Legacy pump: SKC; $9 \mathrm{~L} \mathrm{~min}^{-1}$; STERLITECH Polycarbonate filters: $\varnothing=37 \mathrm{~mm}$ ).

$\mathrm{PM}_{2.5}$ samples were analyzed to determine the watersoluble ionic fraction (Perrone et al., 2012). Water-soluble ions were extracted by ultrapure water (Milli-Q) in an ultrasonic bath $\left(20 \mathrm{~min}\right.$; SOLTEC SONICA $\left.{ }^{\circledR}\right)$. Cations $\left(\mathrm{Na}^{+}\right.$, $\mathrm{NH}_{4}^{+}, \mathrm{K}^{+}, \mathrm{Mg}^{2+}$ and $\mathrm{Ca}^{2+}$ ) have been determined by a Dionex ICS-90 (Ion Pac CS12A-5 $\mu$ m column, using methanesulfonic acid as eluent in an isocratic concentration of $0.4 \mathrm{M}$ at $\left.0.5 \mathrm{~mL} \mathrm{~min}^{-1}\right)$. Anions $\left(\mathrm{Cl}^{-}, \mathrm{NO}_{3}^{-}, \mathrm{SO}_{4}^{2-}\right)$, together with mono and dicarboxylic acids (formiate, acetate, propionate, oxalate, malonate, succinate and glutarate), were analyzed by a Dionex ICS-2000 (Ion Pac AS11A-5 $\mu \mathrm{m}$ column using $\mathrm{KOH}$ at $1.2 \mathrm{~mL} \mathrm{~min}^{-1}$ with a gradient elution between 1.0 and $28 \mathrm{mM}$ ).

The organic matter (OM) fraction was estimated from PM data (Sect. 2.2.1) both BMH and AMH considering the OM fraction derived from wintertime averaged data contained in previous works (Perrone et al., 2012; Ferrero et al., 2011a). Moreover, for the purpose of the refractive index estimation the OM was divided into the water-soluble OM (WSOM) and the water-insoluble OM (WINSOM). They were calculated 
using a WSOM/TC $(\mathrm{TC}=$ total carbon) coefficient of 0.33 for $\mathrm{BMH}$ data and of 0.61 for $\mathrm{AMH}$ data during wintertime as derived from data reported in Carbone et al. (2010).

Finally, since the determination of aerosol DRE requires the knowledge of the aerosol properties along the whole atmospheric column, the intrinsic limit due to the maximum height of balloon flights ( $800 \mathrm{~m}$ a.g.l.) was overcome using a standard continental-average profile of aerosol chemistry, as defined by the OPAC model (Hess, 1998), for aerosol over $1 \mathrm{~km}$.

Accordingly, three broad-range altitude layers were considered: $\mathrm{BMH}$ (from ground to $\mathrm{MH}$ ), $\mathrm{AMH}$ (from $\mathrm{MH}$ to $\sim 1 \mathrm{~km}$ ) and free troposphere (FT: $1-11 \mathrm{~km})$.

The reliability of all the aforementioned assumptions will be discussed in Sect. 3.2.1 through a careful validation of the results with AERONET (columnar validation) and Aethalometer data (validation along the profile).

\subsection{Aerosol optical properties}

Aerosol optical properties were calculated along vertical profiles using a Mie code (Bohren and Huffman, 1983) to subsequently evaluate the aerosol DRE (Sects. 2.4 and 3.4) that requires the extinction coefficient $b_{\text {ext }}$ (the sum of scattering and absorption coefficients), the single-scattering albedo (SSA) and the aerosol phase function $(P)$ as input parameters.

For this purpose the scattering and absorption coefficients $\left(b_{\text {sca }}\right.$ and $\left.b_{\text {abs }}\right)$ were calculated from the integration of the corresponding scattering and absorption efficiencies $\left(Q_{\text {sca }}\right.$ and $Q_{\text {abs }}$ ) over the whole number-size distribution (Seinfeld and Pandis, 1998):

$b_{\text {sca } / \mathrm{abs}}=\int_{0}^{D_{p}^{\max }} \frac{\pi D_{p}^{2}}{4} Q_{\text {sca } / \mathrm{abs}}(m, x) n\left(D_{p}\right) \mathrm{d} D_{p}$,

where $m$ and $x$ are the aerosol complex refractive index and the size parameter, respectively, while $n\left(D_{p}\right)$ represents the number-size distribution as a function of aerosol diameter $\left(D_{p}\right)$.

From the knowledge of $b_{\text {sca }}$ and $b_{\text {abs }}$ profiles, the SSA along height was calculated:

$\mathrm{SSA}=\frac{b_{\mathrm{sca}}}{b_{\mathrm{sca}}+b_{\mathrm{abs}}}$.

Finally, the aerosol phase function $P$ is defined as the normalization of the Mie scattering function over the whole $4 \pi$ spherical angle. For an aerosol characterized by a complex refractive index $m$ and a size parameter $x, P(\theta, x, m)$ is defined as follows (Crosbie and Davidson, 1985):

$P(\theta, x, m)=\frac{i(\theta, x, m)}{\frac{1}{2} \int_{0}^{\pi} i(\theta, x, m) \sin \theta \mathrm{d} \theta}$, where $i(\theta)$ is the Mie scattering function which, for unpolarized light, is the average between the perpendicular and parallel components: $i_{1}(\theta)$ and $i_{2}(\theta)$, respectively.

The aerosol optical properties were calculated over five wavelengths (270, 441, 675, 880 and $3200 \mathrm{~nm})$ in order to cover the solar spectrum (Sect. 2.4); moreover, three of them $(441,675$ and $880 \mathrm{~nm})$ represent the main bands used in the AERONET network allowing the validation of the methodology presented here (Sect. 3.2).

It has to be noticed that the calculation of aerosol optical properties (Eqs. 5-7) requires an accurate knowledge of the aerosol refractive index, the aerosol size-distribution, the aerosol shape and the aerosol mixing state.

As these basic aerosol properties (chemistry, size, shape and mixing state) can seriously affect the optical properties calculation, in the following sections we discuss: (1) the assumptions used in the calculations and their applicability (shape and mixing state; Sect. 2.3.1), (2) the methodology followed to calculate the aerosol refractive index (Sect. 2.3.2) and (3) the aerosol size-distribution treatment starting from OPC data (Sect. 2.3.3). In this respect, particular attention has been given to the choice of the method for calculating the refractive index and to the introduction of appropriate corrections to the aerosol number-size distributions measured by the OPC.

\subsubsection{Assumptions}

The experimental package used for measuring vertical aerosol profiles allowed determining the aerosol chemistry and the aerosol size distribution while no information about aerosol shape and mixing state was available.

Consequently, aerosol particles were assumed as internally mixed and spherical. These two assumptions are logically connected and based on previous observations conducted over the investigated sites.

The first assumption (internal mixing) is related to the observation that optical properties were calculated along vertical profiles (within and above the mixing layer) and not in proximity of emission sources (i.e., close to a traffic line) thus giving the time for particles to age and promote an internal mixing. As a matter of fact, the aging along vertical profiles is reported in literature (McMeeking et al., 2011; Cahill et al., 2012; Morgan et al., 2010; Ferrero et al., 2012; Moroni et al., 2013) and it is also described in Sect. 3.1.2. This behavior is also supported by several observations conducted in the past along vertical profiles (more than 300 profiles between 2005 and 2008) over the investigated sites (MI and TR) reported in Ferrero et al. (2012) and in Moroni et al. (2013). During these experiments it was evidenced (through size-distribution analysis, chemical speciation and SEM-EDS analysis) an increase of the mean size of aerosol with height that, along with the observed increase in secondary aerosol components (i.e., ammonium nitrate), sphericity and correlation among fine aerosol particles, indicated the influence of recurrent aging 
dynamics; moreover, SEM data evidenced the internal mixing state of most of the collected particles.

These results support the use of the internal mixing scenario and, at the same time, the assumption of sphericity as reasonable for the context of this application.

\subsubsection{Aerosol refractive index}

The complex refractive index $(m=n+i k)$ of aerosol was calculated considering a hybrid internal-external mixing scenario. The coarse $\left(D_{p}>1 \mu \mathrm{m}\right)$ and fine $\left(D_{p} \leq 1 \mu \mathrm{m}\right)$ particles were considered externally mixed, each one characterized by its proper value of $m$ calculated using the internal mixing scenario (Ferrero et al., 2011a; Sect. 2.3.1). Coarse particles $\left(D_{p}>1 \mu \mathrm{m}\right)$ were assumed to be composed of dust ( $m$ of dust aerosol), while $m$ for fine particles was calculated from the measured $\mathrm{PM}_{2.5}$ chemical composition (Sects. 2.2.2 and 3.1) using the Bruggeman mixing rule (or effective medium approximation: EMA) (Stier et al., 2007; Aspnes 1982; Heller, 1965; Bruggeman, 1935). The EMA does not consider a simple coated sphere assumption but it is a part of more general mixing rule formulation resumed in Aspnes (1982) as follows:

$$
\frac{\varepsilon_{\mathrm{eff}}-\varepsilon_{\mathrm{h}}}{\varepsilon_{\mathrm{eff}}+2 \varepsilon_{\mathrm{h}}}=\sum_{i=1}^{n} f_{i} \frac{\varepsilon_{i}-\varepsilon_{\mathrm{h}}}{\varepsilon_{i}+2 \varepsilon_{\mathrm{h}}}
$$

where $\varepsilon_{\text {eff }}$ is the complex effective dielectric constant of the mixture $\left(m_{\text {eff }} \approx \sqrt{\varepsilon_{\text {eff }}}\right)$ and $\varepsilon_{i}$ and $f_{i}$ are the complex dielectric constant and the volume fraction, respectively, of the $i$ th component; finally, $\varepsilon_{\mathrm{h}}$ represents the dielectric function of the host medium.

Depending on the choice of host medium, equation 8 can originate three different mixing rules: (1) Maxwell-Garnett (MG) if the host medium is one of the components $\left(\varepsilon_{i}=\varepsilon_{\mathrm{h}}\right)$ (Stier et al., 2007; Schuster et al., 2005; Bohren and Huffman, 1983; Aspnes, 1982; Heller, 1965) and in this case it is possible to refer to the Maxwell-Garnett as coated sphere assumption; (2) Lorentz-Lorenz (LL) if the host medium is the vacuum $\left(\varepsilon_{\mathrm{h}}=1\right)$ (Liu and Daum, 2008; Aspnes, 1982; Heller, 1965) and (3) Bruggeman (BR or EMA) if no choice of host medium is made, and inclusions are considered embedded in the effective medium itself $\left(\varepsilon_{\mathrm{h}}=\varepsilon_{\text {eff }}\right)$ (Stier et al., 2007; Aspnes, 1982; Heller, 1965, Bruggeman, 1935). Stier et al. (2007) and Aspnes (1982) point out that the EMA overcomes the dilemma of the choice of host medium among the various aerosol components. From this point of view, the EMA considers all the possible positions of each aerosol component (BC, dust, water-soluble materials, etc.) with respect to the others. Thus, it allows simulating the real complexity of aerosols and it is suitable for use in calculating the

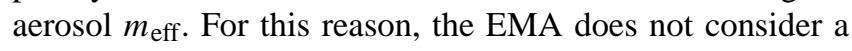
simple coated sphere assumption and implies that the left part of the aforementioned equation vanishes giving the Eq. (9) reported here below:

$\sum_{i=1}^{n} f_{i} \frac{\varepsilon_{i}-\varepsilon_{\mathrm{eff}}}{\varepsilon_{i}+2 \varepsilon_{\mathrm{eff}}}=0$.

As the EMA simulates the real complexity of aerosols (considering all possible positions of each component in an aerosol particle), it avoids the risk of overestimating the imaginary part $(k)$ of $m$, thus reducing the uncertainties, as instead happens using both the linear volume-average and the linear mass-average mixing rules in the presence of highly absorbing inclusions (i.e., BC) in a non-absorbing medium (i.e., $\mathrm{NH}_{4} \mathrm{NO}_{3}$ and $\left(\mathrm{NH}_{4}\right)_{2} \mathrm{SO}_{4}$ ) (Stier et al., 2007; Lesins et al., 2002; Chýlek et al., 1995).

Thus, vertical profiles of aerosol refractive index were calculated from the aerosol chemical composition along height using the EMA; in this respect the missing mass was assigned equally to both water and dust (Ferrero et al., 2011a) since it has been shown that a certain amount of water is bound to particles (Subramanian et al., 2007; Hueglin et al., 2005; Rees et al., 2004), and also that this amount is comparable to dust in winter (Hueglin et al., 2005; Rees et al., 2004). Densities $(\rho)$ of pure compounds were used to estimate the volume fraction of each aerosol component (Fierz-Schmidhauser et al., 2010; Pesava et al., 2001; Chazette and Liousse, 2001; Heller, 1965).

A detailed description of refractive indexes and densities of pure aerosol components used in the calculation, and yet successfully applied along vertical profiles, is reported in Ferrero et al. (2011a). The density and refractive index values were carefully chosen from the literature (especially for BC) considering only state-of-the-art values; here we summarize these choices. Refractive indexes as a function of $\lambda$ for water-soluble components, water-insoluble components and dust were that reported by Hess (1998), while the chosen value for the $\mathrm{BC}$ refractive index was that suggested in Bond and Bergstrom (2006): $1.85+i 0.71$. However, the latter value is referred to $550 \mathrm{~nm}$ only and thus, the wavelength dependence of $\mathrm{BC}$ refractive index reported in Ackerman and Toon (1981), and yet successfully used in Ferrero et al. (2011a), was applied to the Bond and Bergstrom (2006) value in order to calculate the aerosol optical properties over the whole solar spectrum. The density $(\rho)$ values were 1.75 , $1.45,1.45$ and $2.6 \mathrm{~g} \mathrm{~cm}^{-3}$ for ionic components WSOM, WINSOM and dust, respectively. These values lie at the midpoint of published data reported in Ferrero et al. (2011a) and references therein.

Since the aforementioned choices, especially for what concern the BC density and refractive index would affect the aerosol refractive index calculation, a sensitivity test was conducted varying the density and refractive index of pure $\mathrm{BC}$ in input to the EMA. In particular, results obtained using the density $\left(1.8 \mathrm{~g} \mathrm{~cm}^{-3}\right)$ and the refractive index $(1.85+0.71 i)$ suggested in Bond and Bengstrom (2006) were compared to (1) those obtained with the density 
$\left(1.0 \mathrm{~g} \mathrm{~cm}^{-3}\right)$ and the refractive index $(1.75+0.44 i)$ used in the OPAC software (Hess et al., 1998) and (2) those obtained with the density $\left(2.0 \mathrm{~g} \mathrm{~cm}^{-3}\right)$ and the refractive index $(2+1 i)$ reported in Roessler (1984). These two references are of high importance as they report the lowest density (never observed) and one of the highest imaginary part reported in literature, respectively. Results are discussed in Sect. 3.2.1.

Finally, the aerosol refractive index was determined point by point along vertical profiles, considering the hygroscopic growth of the aerosol:

$D_{\text {wet }}=D_{\text {dry }} \cdot\left(\frac{1-\mathrm{RH}}{1-\mathrm{DRH}}\right)^{-\varepsilon}$,

where $\mathrm{RH}$ is the ambient relative humidity, $D_{\mathrm{dry}}$ is the aerosol diameter at the deliquescence relative humidity (DRH) and $D_{\text {wet }}$ is the aerosol diameter at ambient $\mathrm{RH} ; \varepsilon$ is the coefficient controlling the aerosol's hygroscopic growth. Since the ground-level chemical composition of dry aerosol measured at TR, MI and ME (Sect. 3.1.2) was similar to that reported in Randriamiarisoa et al. (2006) and Raut and Chazette (2008), we set $\varepsilon$ accordingly to 0.26 .

DRH was estimated using the aerosol's chemical composition for each site along all the profiles as input to the thermodynamic aerosol inorganic model (E-AIM Model-II) (Clegg et al., 1998) (http://www.aim.env.uea.ac.uk/aim/aim. $\mathrm{php}$ ). This is a state-of-the-art aerosol thermodynamic model for the $\mathrm{H}^{+}-\mathrm{NH}_{4}^{+}-\mathrm{SO}_{4}^{2-}-\mathrm{NO}_{3}^{-}$-carboxylic acids- $\mathrm{H}_{2} \mathrm{O}$ composition of the aerosol (Zhang et al., 2000). This model had been already used to accurately predict aerosol DRH (Ferrero et al., 2013; Hueglin et al., 2005; Pathak, 2004). DRH values are discussed in Sect. 3.1.2. From hygroscopic growth, the EMA was applied point by point along height to calculate the final aerosol refractive index every $3.0 \mathrm{~m}$ for each profile.

As the aforementioned choices (EMA, $m$ and $\rho$ for pure components, hygroscopic growth) can seriously affect the optical properties calculation, the calculated refractive index and the aerosol optical properties were validated in detail, as presented in Sect. 3.2.

\subsubsection{Aerosol size distribution}

The determination of aerosol optical properties requires an accurate knowledge of the aerosol size distribution.

In this study, the aerosol size distribution was measured using the OPC Grimm $1.107(\lambda=655 \mathrm{~nm})$ that classifies the aerosol particles in terms of optical equivalent diameter which is, as defined by Howell et al. (2006), "the diameter of a sphere of known refractive index (that of polystyrene latex spheres of calibration) that scatters light as efficiently as the real particle in question". This effect originates the "undersizing" problem, which occurs due to the OPC calibration with polystyrene latex spheres (PLS; $m=1.58$ at $655 \mathrm{~nm}$; Ma et al., 2003) whose refractive index has usually a larger real part compared to ambient aerosol (Sect. 3.2.1) (Guyon et al., 2003; Liu and Daum, 2008; Schumann, 1990). Moreover, the OPC has a PLS equivalent size range between 0.25 and $32 \mu \mathrm{m}$, which originates a "truncation effect". Thus, both the "undersizing" and the "truncation effect" need to be compensated to calculate the aerosol optical properties.

The "undersizing" was solved correcting the OPC size channels to account for the ambient aerosol refractive index $m$; the OPC response function $(S$ : the partial light scattering cross section of the particle related to the specific optical design of the OPC) was computed at $655 \mathrm{~nm}$ as follows (Baron and Willeke, 2005; Heyder and Gebhart, 1979):

$$
\begin{aligned}
& S\left(\theta_{0}, \Delta \Omega, x, m\right)= \\
& \frac{\lambda^{2}}{4 \pi^{2}} \iint_{\Delta \Omega} i(\theta, \Phi, x, m) \sin \theta \mathrm{d} \theta \mathrm{d} \Phi,
\end{aligned}
$$

where $\theta_{0}$ represents the mean scattering angle of the optical arrangement, $\Delta \Omega$ the receiver aperture, $x$ the dimensionless size parameter, $m$ the refractive index and $i(\theta, \varphi, x, m)$ the Mie scattering function composed by the perpendicular and parallel components: $i_{1}(\theta, x, m)$ and $i_{2}(\theta, x, m)$, respectively. The optical arrangement of the OPC 1.107 consists of (1) a wide angle parabolic mirror $\left(121^{\circ}\right.$; from 29.5 to $150.5^{\circ}$; $\theta_{0}=90^{\circ}$ ) that focuses scattered light on the photodetector located on the opposite side and (2) $18^{\circ}$ of direct collected scattered light on the photodetector (from 81 to $99^{\circ} ; \theta_{0}=90^{\circ}$ ) (Heim et al., 2008).

The response function was calculated both for PLS ( $\left.S_{\text {PLS }}\right)$ and for ambient aerosol $\left(S_{\mathrm{AMB}}\right)$ along each vertical profile, within and above the mixing layer. The refractive indexes of ambient aerosol used in $S_{\mathrm{AMB}}$ calculations were calculated as reported in Sect. 2.3.1: (1) $m$ for fine particles calculated applying the EMA (Sect. 2.3.1) and (2) $m$ of dust for coarse particles. Table 1 shows the columnar means of the new size corrected channels for TR, MI and ME: results agreed with literature studies (Ferrero et al., 2011a; Liu and Daum, 2008; Schumann, 1990).

The second effect (truncation effect) made the accumulation mode only partially measured (lowest equivalent PLS size of OPC: $0.25 \mu \mathrm{m}$ ) while, the coarse mode was completely defined. No measurements were available for Aitken mode particles $\left(D_{p}<0.1 \mu \mathrm{m}\right)$. Even if a negligible error $(\sim 2-4 \%)$ comes from not considering the Aitken mode in the optical properties calculation (Bond and Bergstrom, 2006; Guyon et al., 2003; Liu and Daum, 2008; Randriamiarisoa et al., 2006), the truncation effect in the accumulation mode cannot be neglected and has to be solved.

For this purpose, a log-normal interpolation of the aerosol number-size distribution was conducted for each OPC data measured along vertical profiles to complete the aerosol sizedistribution function $n\left(D_{p}\right)$. This procedure has to be conducted only after the correction of the OPC size channels (Eq. 10) and had been already successfully applied in Ferrero et al. (2011a), Deshler (2003) and Angelini et al. (2009). 
Table 1. Original size channels of OPC Grimm 1.107 calibrated with PLS (left side) and corrected (right side, columnar average) for the ambient refractive index determined over TR, MI and ME.

\begin{tabular}{|c|c|c|c|c|}
\hline \multicolumn{2}{|c|}{ Instrumental size } & \multicolumn{3}{|c|}{ Ambient size $(\mu \mathrm{m})$} \\
\hline OPC Channel & PLS $(\mu \mathrm{m})$ & Terni & Milano & Merano \\
\hline 1 & 0.25 & 0.27 & 0.27 & 0.26 \\
\hline 2 & 0.28 & 0.30 & 0.30 & 0.30 \\
\hline 3 & 0.30 & 0.32 & 0.33 & 0.32 \\
\hline 4 & 0.35 & 0.38 & 0.39 & 0.38 \\
\hline 5 & 0.40 & 0.46 & 0.47 & 0.45 \\
\hline 6 & 0.45 & 0.52 & 0.53 & 0.52 \\
\hline 7 & 0.50 & 0.56 & 0.58 & 0.56 \\
\hline 8 & 0.58 & 0.75 & 0.79 & 0.75 \\
\hline 9 & 0.65 & 0.80 & 0.91 & 0.81 \\
\hline 10 & 0.70 & 0.90 & 0.94 & 0.90 \\
\hline 11 & 0.80 & 1.00 & 1.06 & 1.00 \\
\hline 12 & 1.00 & 1.35 & 1.35 & 1.33 \\
\hline 13 & 1.30 & 1.78 & 1.78 & 1.78 \\
\hline 14 & 1.60 & 2.14 & 2.14 & 2.14 \\
\hline 15 & 2.00 & 2.40 & 2.40 & 2.40 \\
\hline 16 & 2.50 & 2.82 & 2.82 & 2.82 \\
\hline 17 & 3.00 & 3.67 & 3.67 & 3.67 \\
\hline 18 & 3.50 & 4.62 & 4.62 & 4.62 \\
\hline 19 & 4.00 & 5.01 & 5.01 & 5.01 \\
\hline 20 & 5.00 & 5.89 & 5.89 & 5.89 \\
\hline 21 & 6.50 & 9.55 & 9.55 & 9.55 \\
\hline 22 & 7.50 & 10.72 & 10.72 & 10.72 \\
\hline 23 & 8.50 & 12.16 & 12.16 & 12.16 \\
\hline 24 & 10.00 & 16.03 & 16.03 & 16.03 \\
\hline 25 & 12.50 & 22.65 & 22.65 & 22.65 \\
\hline 26 & 15.00 & 29.85 & 29.85 & 29.85 \\
\hline 27 & 17.50 & 37.15 & 37.15 & 37.15 \\
\hline 28 & $>20.00$ & $>44.67$ & $>44.67$ & $>44.67$ \\
\hline
\end{tabular}

As the aerosol optical properties are closely dependent on the reliability of the aerosol number-size distribution, the main parameters describing the aerosol size distribution (geometric mean diameter and geometric standard deviation), together with the aerosol optical properties, were validated with care, as explained in Sect. 3.2. Sensitivity tests related to the size-distribution correction and interpolation are reported and discussed in Ferrero et al. (2011a) and were not repeated here.

\subsection{Radiative transfer and heating-rate calculations}

Aerosol scattering and absorption of solar radiation modify the intensity and spectral distribution of surface incoming solar radiation. Thus, aerosol DRE can be estimated by means of radiative transfer model (RTM) simulations. In this work the RTM libRadtran (Mayer and Kylling, 2005) was used for this purpose, adopting as radiative transfer equation solver the discrete ordinate code disort (Stamnes et al., 1988) with 18 streams. The correlated- $k$ approach of Kato (Kato et al.,
1999) was used to compute the atmospheric spectral transmittance taking into account the absorption coefficients of different gases.

RTM simulations were performed in cloud-free conditions (as the vertical profile measurements) at the three measurement sites (TR, MI and ME) at $15 \mathrm{~min}$ intervals for each day of the measurement campaign, from 11:00 to 13:45 UTC. The average was computed in order to obtain an estimate of the maximum radiative forcing of aerosol, which is generally observed around noon.

Three main inputs were used in the RTM simulations, namely, (1) aerosol optical properties along vertical profiles, (2) atmospheric profiles of gases and meteorological parameters and (3) surface albedo.

The vertical profiles of aerosol optical properties ( $b_{\text {ext }}$, SSA, $P(\theta))$ that were used as input for the RTM were the ones calculated over TR, MI and ME, as reported in the previous section (Sect. 2.3).

Atmospheric profiles of pressure, temperature, air density, ozone, oxygen, water vapor, $\mathrm{CO}_{2}$ and $\mathrm{NO}_{2}$ concentrations were defined by using the standard atmospheric data as defined by Anderson et al. (1986), for Midlatitude Winter. The vertical resolution of these profiles was $1 \mathrm{~km}$ from 0 to $25 \mathrm{~km}$ a.m.s.l., $2.5 \mathrm{~km}$ from 25 to $50 \mathrm{~km}$ a.m.s.l. and $5 \mathrm{~km}$ from 50 to $120 \mathrm{~km}$ a.m.s.1.

Finally, surface albedo values used for the simulation derive from retrievals from the moderate resolution imaging spectroradiometer (MODIS) V005 climate modeling grid (CMG) Albedo Product (MCD43C3). For each site, the average value at the nearest pixel during the measurement campaign was adopted.

The instantaneous aerosol DRE $\left(\mathrm{W} \mathrm{m}^{-2}\right)$ was quantified as the change in the net radiative flux between the atmospheric conditions with and without the aerosols in the atmosphere as follows:

$\mathrm{DRE}_{z}=F_{\mathrm{aer}, z}-F_{w / o-\mathrm{aer}, z}$

where $F$ is the radiative flux, and the subscripts aer, $z$ and $w / o-$ aer, $z$ refers to the atmospheric conditions with and without aerosol at the height $z$, respectively.

Since the atmospheric aerosol is characterized by a significant absorptive capacity (Sect. 3.3), the difference between the DRE at the top and the bottom of each atmospheric layer represents the instantaneous radiative power density absorbed by the aerosol within that atmospheric layer $\left(\triangle \mathrm{DRE}_{\mathrm{ATM}} ; \mathrm{W} \mathrm{m}^{-2}\right)$ as follows (Chakrabarty et al., 2012; Kedia et al., 2010):

$\Delta \mathrm{DRE}_{\mathrm{ATM}}=\mathrm{DRE}_{z+\Delta z}-\mathrm{DRE}_{z}$,

where $\Delta z$ is the differential thickness within each atmospheric layer (each measuring point along vertical profiles; Sect. 2.1).

$\triangle \mathrm{DRE}_{\mathrm{ATM}}$ is expressed in $\mathrm{W} \mathrm{m}^{-2}$ which is the common metric used in literature to quantify the integrated radiative 
power density absorbed by the aerosol in the atmospheric layer; this situation occurs as usually the aerosol absorption in the atmosphere is evaluated over altitude thick layer of the atmosphere and/or over the whole atmospheric column (Heald et al., 2014; IPCC, 2013; Bond et al., 2013; Das and Jayaraman, 2011; Kedia et al., 2010).

However, in order to study the absorptive DRE (ADRE) of the aerosol in the atmosphere along continuous highresolution vertical profiles, the aforementioned metric could be misleading, as absolute values of $\triangle \mathrm{DRE}_{\mathrm{ATM}}$ depend on the thickness of the layer $\Delta z$ across which the DRE difference is computed. To compare measurements taken at different sites with a different vertical resolution, the ADRE was computed simply normalizing $\triangle \mathrm{DRE}_{\mathrm{ATM}}$ by the thickness $\Delta z$ :

$\mathrm{ADRE}=\frac{\Delta \mathrm{DRE}_{\mathrm{ATM}}}{\Delta_{z}}$.

In this way, the ADRE represents the radiative power absorbed by the aerosol for unit volume of the atmosphere $\left(\mathrm{W} \mathrm{m}^{-3}\right)$ and allows describing continuous vertical profiles of atmospheric absorption induced by aerosol even comparing data taken at different sites. Another illustration of the ADRE meaning is that it is the vertical derivative of the DRE (dDRE/dz) as follows from Eq. (14).

Moreover, the ADRE can be directly related to the atmospheric heating rate (HR; see below). In fact, on the basis of the energy conservation principle, the absorbed radiant power must heat the atmospheric layer; the instantaneous HR is conventionally given by (Chakrabarty et al., 2012; Kedia et al., 2010):

$\mathrm{HR}=\frac{\partial T}{\partial t}=-\frac{g}{C_{p}} \frac{\Delta \mathrm{DRE}_{\mathrm{ATM}}}{\Delta P}$,

where $\partial T / \partial t$ represents the instantaneous HR $\left(\mathrm{K} \mathrm{day}^{-1}\right)$ of each atmospheric layer, $g$ is the acceleration due to gravity, $C_{p}\left(1005 \mathrm{~J} \mathrm{~kg}^{-1} \mathrm{~K}^{-1}\right)$ is the isobaric specific heat of dry air, $\Delta P$ is the pressure difference between the top and the bottom of each atmospheric layer. From Eq. (15), considering the relationship between atmospheric pressure and height through the hydrostatic equation $(\mathrm{d} p=-\rho g \mathrm{~d} z)$, it is possible to relate the HR linearly to the ADRE in each atmospheric layer:

$\mathrm{HR}=\frac{\partial T}{\partial t}=\frac{1}{\rho C_{p}} \frac{\Delta \mathrm{DRE}_{\mathrm{ATM}}}{\Delta z}=\frac{1}{\rho C_{p}} \cdot \mathrm{ADRE}$.

The ADRE and HR behavior along vertical profiles is discussed in Sect. 3.4.

\section{Results and discussion}

We measured the $\mathrm{BC}$ and aerosol vertical profiles to determine their direct radiative effect. The obtained results are discussed here in order to highlight first the BC vertical distribution in relation to the MH (Sect. 3.1). Then, vertical profiles of aerosol optical properties are validated in Sect. 3.2 and discussed in Sect. 3.3. Finally, the aerosol DRE along height is presented together with considerations on possible feedbacks on lower troposphere (Sect. 3.4). All averaged data are reported here as mean \pm mean standard deviation.

\subsection{Vertical profile measurements}

\subsubsection{Black carbon and aerosol profiles}

The main features of BC and aerosol vertical distribution during the campaign can be highlighted considering, as a case study, the vertical profiles measured on 28 January 2010 (13:45-14:26 UTC) over TR; they are reported in Fig. 2 together with the corresponding potential temperature $(T)$ and RH profiles.

Figure 2 highlights that the $\mathrm{BC}$ and the total particlenumber concentrations were constrained close to ground, within the first $170 \mathrm{~m}$ a.g.l., where a strong negative gradient of both of them was present. At the same height an evident decrease of $\mathrm{RH}(-3.5 \%)$ and a small increase in $T(+0.7 \mathrm{~K})$ were observed, allowing to set the $\mathrm{MH}$ at $170 \mathrm{~m}$.

Thus, considering changes across the $\mathrm{MH}$, the $\mathrm{BC}$ concentration decreased going from $\mathrm{BMH}$ to $\mathrm{AMH}$ characteristics by $-60.4 \pm 2.3 \%$ (from $5.63 \pm 0.16$ to $2.23 \pm 0.05 \mu \mathrm{g} \mathrm{m}{ }^{-3}$ for $\mathrm{BC}$ ) and the aerosol concentration by $-35.4 \pm 0.2 \%$ (from $869 \pm 2$ to $562 \pm 2 \mathrm{~cm}^{-3}$ for aerosol). Consequently, the vertical profiles reported in this case study (Fig. 2) indicate that (1) BC and aerosol concentrations were shaped in the same way by atmospheric turbulence and constrained within the $\mathrm{MH}$; (2) $\mathrm{BC}$ experienced a higher concentration drop at the $\mathrm{MH}$ than the aerosol number concentration did.

In order to better investigate these features, all the vertical profiles measured over the investigated basin valleys (TR, MI and ME) were statistically averaged for each site.

As reported in previous works (Ferrero et al., 2011a, 2012), a way to average vertical profile data by taking the daily evolution of the $\mathrm{MH}$ into account, is to consider the relative position of each measured data point in respect to the MH. Thus, vertical profiles were first normalized, introducing a standardized height $\left(H_{\mathrm{s}}\right)$ calculated as follows:

$H_{\mathrm{s}}=\frac{z-\mathrm{MH}}{\mathrm{MH}}$,

where $z$ is the height above ground. $H_{\mathrm{S}}$ assumes a value of 0 at the $\mathrm{MH}$, and values of -1 and 1 at ground-level and at twice the $\mathrm{MH}$, respectively.

The MH was determined applying the gradient method (Sect. 2.2) to each profile of aerosol concentration ( $p-\mathrm{MH})$, $T(T-\mathrm{MH})$ and $\mathrm{RH}(\mathrm{RH}-\mathrm{MH})$. Figure 3 shows an excellent correlation $\left(R^{2}>0.9\right)$ with linear best fits close to the ideal ones; this result illustrates the reliability and physical interconsistence of the $\mathrm{MH}$ determination from different parameters. Therefore, for the purpose of this work and for using of Eq. (17), we are going to refer to the $\mathrm{MH}$ as that derived 


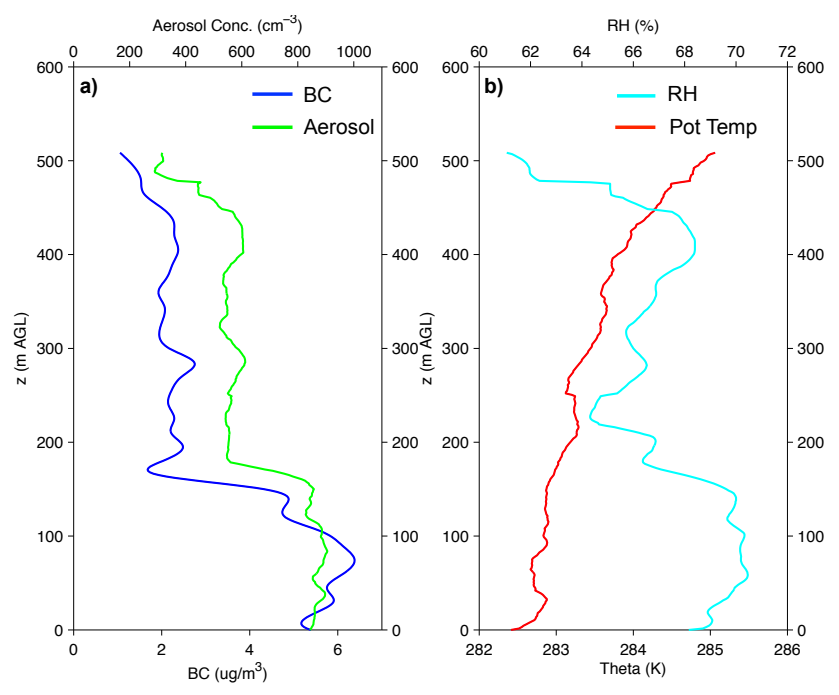

Figure 2. Vertical profiles measured over TR on 28 January 2010 (13:45-14:26 UTC): (a) BC (blue line) and aerosol (green line, OPC total particle-number concentration); (b) potential temperature (red line) and relative humidity (light blue line).

from the aerosol concentration gradient ( $p-\mathrm{MH})$, hereinafter indicated simply as MH.

The average $\mathrm{MH}$ measured in the three sites was $142 \pm$ $22 \mathrm{~m}$ (TR), $272 \pm 50 \mathrm{~m}$ (MI) and $173 \pm 42 \mathrm{~m}$ (ME). These values reflected a common meteorological situation for the Italian basin valleys, characterized by conditions of high atmospheric stability. Reported MH values are also in agreement with those previously reported for TR and MI in Ferrero et al. (2012).

Next the standardized vertical profiles were averaged. Figure 4 shows the resulting statistical mean profiles calculated over TR, MI and ME, for both BC and aerosol number concentration; some common behaviors can be observed among the three sites:

1. At the $\mathrm{MH}\left(H_{\mathrm{S}}=0\right)$ a marked concentration drop of both $\mathrm{BC}$ and total aerosol concentration was observed. Crossing the mixing height, $\mathrm{BC}$ concentrations decreased over TR by $-69.1 \pm 5.5 \%$ (from $5.63 \pm$ 0.55 to $1.67 \pm 0.36 \mu \mathrm{g} \mathrm{m}^{-3}$ ), over MI by $-66.2 \pm$ $7.8 \%$ (from $7.57 \pm 1.28$ to $2.03 \pm 0.34 \mu \mathrm{g} \mathrm{m}^{-3}$ ) and over ME by $-48.4 \pm 5.3 \%$ (from $2.75 \pm 0.38$ to $1.35 \pm 0.17 \mu \mathrm{g} \mathrm{m}^{-3}$ ). Aerosol concentrations (from BMH to AMH) behave similarly, decreasing over TR by $-46.5 \pm 7.3 \%$ (from $792 \pm 58$ to $434 \pm 71 \mathrm{~cm}^{-3}$ ), over MI by $-39.0 \pm 7.3 \%$ (from $913 \pm 120$ to $506 \pm$ $50 \mathrm{~cm}^{-3}$ ) and over ME by $-23.9 \pm 4.3 \%$ (from $427 \pm$ 45 to $326 \pm 43 \mathrm{~cm}^{-3}$ ), respectively. Thus, the experimental results evidenced the crucial role played by the $\mathrm{MH}$ in shaping both the $\mathrm{BC}$ and aerosol profiles over basin-valleys. As a result, elevated $\mathrm{BC}$ and aerosol loadings were present close to the ground. Another common

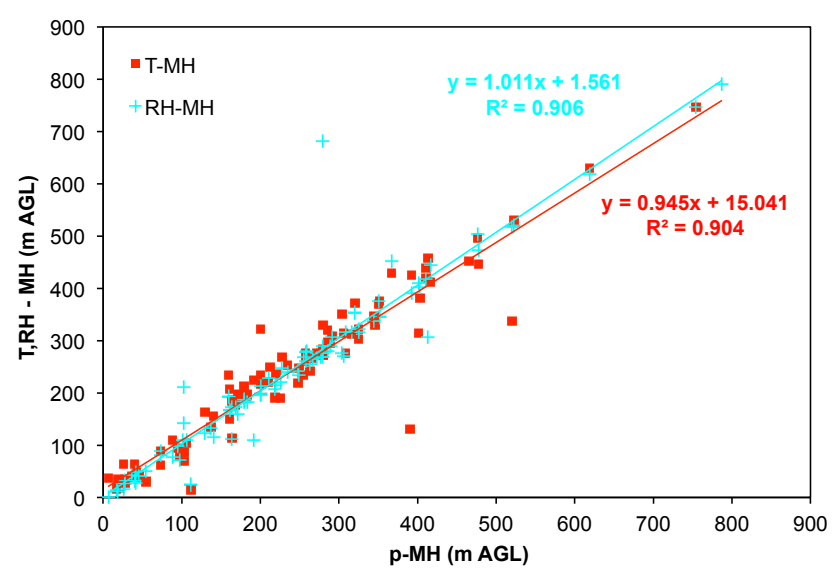

Figure 3. Linear correlation between the mixing height derived from each vertical profile of aerosol concentration ( $p-\mathrm{MH})$ temperature $(T-\mathrm{MH})$ and relative humidity (RH-MH).

behavior appeared: the partial decrease of $\mathrm{BC}$ across the MH was always higher than the decrease measured for the aerosol number concentration; consequently, the relative abundance of $\mathrm{BC}$ in the aerosol decreased along height over the three sites. In fact, considering not only the number concentration, but also the $\mathrm{PM}_{2.5}$ mass concentration profiles (estimated by the OPC) and the volume concentration profiles for particles below $2.5 \mu \mathrm{m}\left(V_{2.5}\right.$, calculated from OPC size distribution), the $\mathrm{BC}$ content in $\mathrm{PM}_{2.5}\left(V_{2.5}\right)$ decreased along height by $-43.2 \pm 7.3 \%(-41.8 \pm 7.5 \%),-47.5 \pm$ $7.9 \%(-45.8 \pm 8.3 \%)$ and $-33.2 \pm 4.9 \%(-33.0 \pm$ $5.4 \%$ ) over TR, MI and ME, respectively, resulting in a vertical change of the $\mathrm{BC}$ aerosol fraction (see also Sect. 3.1.2). This is a general behavior measured over basin valleys under atmospheric stagnant conditions and it is in agreement with BC measurements previously conducted just over MI (Ferrero et al., 2011a). The importance of this behavior is discussed in Sects. 3.2 and 3.3 as the $\mathrm{BC}$ fraction changes affect the aerosol optical properties (i.e., SSA) and its DRE along height.

2. Within the mixing layer itself, higher BC concentrations were found close to the ground in all the three sites (Fig. 4). In particular this ground-level layer affected the first $50-100 \mathrm{~m}$ of atmosphere with a BC concentration increase of $+34.2 \%$ (TR), $+17.3 \%$ (MI) and $+16.1 \%$ (ME) compared to the average $\mathrm{BC}$ concentration measured BMH. This increase of $\mathrm{BC}$ concentration near ground level is related to the proximity to emission sources (traffic, heating, industry) (Trompetter et al., 2013) and was observed for BC only and not for the particle-number distribution. This further strengthens the aforementioned observation of the vertical changes in the $\mathrm{BC}$ aerosol fraction. 

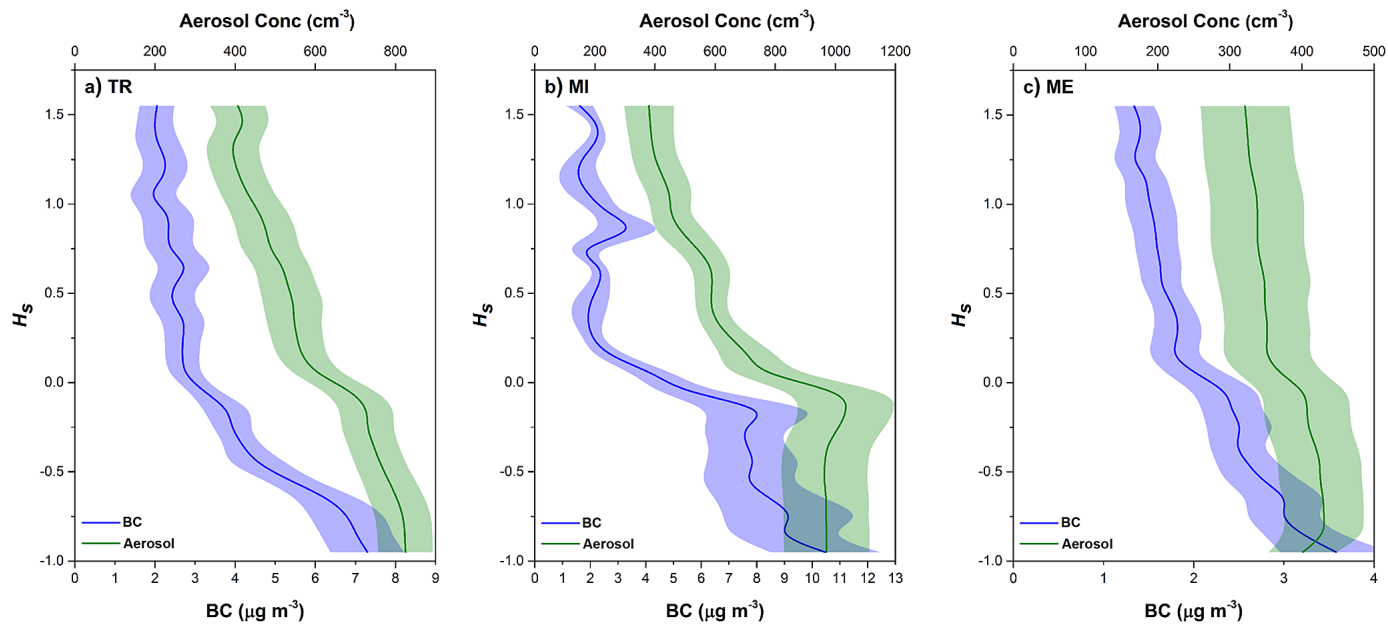

Figure 4. The statistical mean profiles of both BC and aerosol number concentrations along standardized height $H_{\mathrm{S}}$ over TR (a), MI (b) and ME (c).

3. BC concentrations measured AMH were found quite similar over the three sites: $1.67 \pm 0.36 \mu \mathrm{g} \mathrm{m}^{-3}$ for TR, $2.03 \pm 0.34 \mu \mathrm{g} \mathrm{m}^{-3}$ for MI and $1.35 \pm 0.17 \mu \mathrm{g} \mathrm{m}^{-3}$ for ME (Fig. 4), indicating the presence of a relatively constant background $\mathrm{BC}$ concentration value not directly short-term influenced by the source dynamics at ground.

As reported in literature (Samset et al., 2013; Zarzycki and Bond, 2010), a worldwide lack of knowledge about BC vertical distribution is generally present. Thus, the aforementioned results were used in Sects. 3.3 and 3.4 to assess the related vertical behavior of both aerosol optical properties and aerosol DRE over basin valleys.

\subsubsection{Aerosol chemistry along height and DRH}

The optical properties calculation along vertical profiles (Sects. 2.3 and 3.2) requires the knowledge of the whole aerosol chemical composition along height. Thus, in addition to BC (Sect. 3.2.1), the other chemical components (ions, $\mathrm{OM}$; Sect. 2.2.2) in $\mathrm{PM}_{2.5}$ are discussed here. Figure 5 shows the aerosol chemical composition over TR, MI and ME both $\mathrm{BMH}$ and $\mathrm{AMH}$.

As highlighted in the previous section (Sect. 3.2.1), Fig. 5 evidences the decrease of BC fraction from BMH $(8.4 \pm$ $1.0 \%$ over TR, $10.1 \pm 2.3 \%$ over MI and $8.6 \pm 1.5 \%$ over ME) to AMH $(4.5 \pm 1.2 \%$ over TR, $5.3 \pm 1.0 \%$ over MI and $5.5 \pm 1.4 \%$ over ME).

Conversely, the OM fraction increased with height (from $\mathrm{BMH}$ to $\mathrm{AMH}$ ): from $29.5 \pm 3.6$ to $32.4 \pm 8.4 \%$ over TR, from $35.6 \pm 8.2$ to $44.1 \pm 7.4 \%$ over $\mathrm{MI}$ and from $30.4 \pm 5.3$ to $44.2 \pm 7.3 \%$ over ME.

This difference in the vertical behavior of $\mathrm{BC}$ and $\mathrm{OM}$ is related first to the presence of primary sources of $\mathrm{BC}$ within the mixing layer (Trompetter et al., 2013), but also to the possibility of greater secondary aerosol formation AMH.

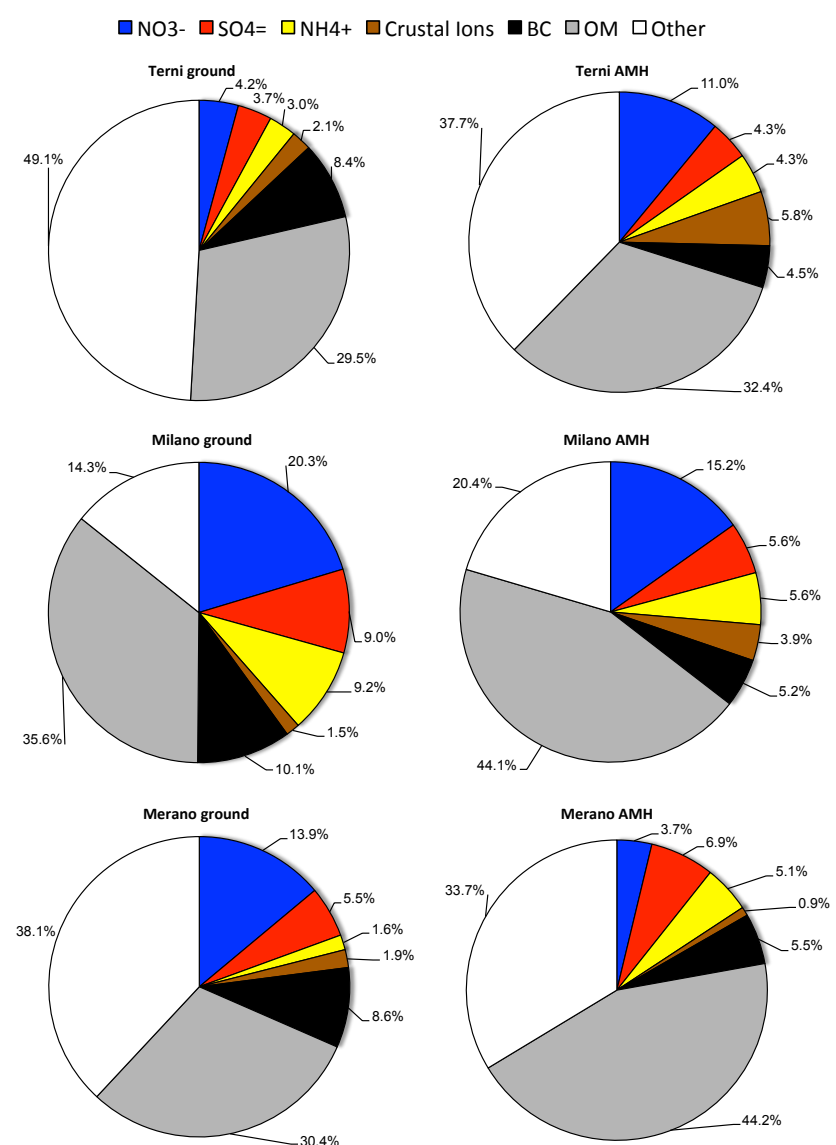

Figure 5. Aerosol chemical composition determined $\mathrm{BMH}$ and AMH for TR, MI and ME. Data shown are the respective aerosol mass fractions of each individual aerosol species. 
This is in agreement with results previously reported over the Po Valley (Ferrero et al., 2011a; Perrone et al., 2010) and also over Europe by many authors (Morgan et al., 2009; Schneider et al., 2006; Hueglin et al., 2005), who all found a lower vertical gradient for organic species.

Ionic species exhibited different behavior over the three sites. Over TR the whole ionic fraction increased $\sim 2$ times going from $\mathrm{BMH}$ to $\mathrm{AMH}$. The mass fraction of $\mathrm{NO}_{3}^{-}, \mathrm{SO}_{4}^{2-}$ and $\mathrm{NH}_{4}^{+}$increased from $4.2 \pm 1.8,3.7 \pm 2.6$ and $3.0 \pm 1.5 \%$ (BMH) to $11.0 \pm 3.6,4.2 \pm 1.1$ and $4.3 \pm 1.4 \%$ (AMH), respectively. This is in agreement with recent studies (Moroni et al., 2013; Ferrero et al., 2012) which point out the presence of an aerosol aging AMH due to both condensation and coagulation.

Over MI the opposite occurred and the ionic fraction globally decreased from $40.0 \pm 9.5 \%$ (BMH) to $30.2 \pm 7.2 \%$ $(\mathrm{AMH})$. This is also in agreement with previous vertical profiles conducted over MI (Ferrero et al., 2010, 2012) which instead underlined a higher role of the OM (see above) in the aerosol aging AMH over the Po Valley.

Over ME the ionic fraction decreased with height (from $23.0 \pm 9.0 \% \mathrm{BMH}$ to $16.7 \pm 2.2 \% \mathrm{AMH}$ ) as in MI. However, while in $\mathrm{MI}$ and $\mathrm{TR} \mathrm{NO}_{3}^{-}$remained the most abundant species $\mathrm{AMH}$, over $\mathrm{ME} \mathrm{SO}_{4}^{2-}$ dominated. This was due to the alternating influence of both continental aerosol (enriched in $\mathrm{SO}_{4}^{2-}$ ) and Po Valley aerosol, that were transported from both north and south, respectively, along the direction of the ME main valley (Sect. 2.1).

All these aspects are crucial in determining the aerosol optical properties because, as reported in Ramana et al. (2010), the ratio of $\mathrm{BC}$ to scattering species (i.e., $\mathrm{SO}_{4}^{2-}$ ) influences the solar-absorption efficiency. Moreover, the same scattering species (i.e., $\mathrm{SO}_{4}^{2-}$ and $\mathrm{NO}_{3}^{-}$) also influence the $\mathrm{DRH}$ at which aerosol water uptake starts, corresponding to a phase change for the aerosol water-soluble compounds which dissociate going from solid to liquid (Martin, 2000; Seinfeld and Pandis, 1998; Potukuchi and Wexler, 1995). Therefore, DRH is of crucial importance to assess the final aerosol optical properties (Di Nicolantonio et al., 2009; Randriamiarisoa et al., 2006).

In this respect, the E-AIM Model II (Sect. 2.3.1) was applied to the $\mathrm{H}^{+}-\mathrm{NH}_{4}^{+}-\mathrm{SO}_{4}^{2-}-\mathrm{NO}_{3}^{-}$-carboxylic acids- $\mathrm{H}_{2} \mathrm{O}$ composition of the aerosol to accurately predict the aerosol DRH for each site both BMH and AMH. BMH values for TR, MI and ME were close each other: 64.5, 67.0 and $65 \%$, respectively. They were in agreement with values measured at ground level in MI by means of an aerosol chamber (Ferrero et al., 2014).

Values of DRH AMH were $55 \%$ (TR), $62 \%$ (MI) and $67 \%$ (ME). The lowest and the highest values were found over TR and ME due to an increase in the nitrate and sulfate fractions, respectively. As already pointed out by Potukuchi and Wexler (1995), an increase in the nitrate (sulfate) fraction leads to lower (higher) DRH.
All the results presented in this section were used to calculate the aerosol optical properties along vertical profiles (Sect. 3.2) following the methodology reported in Sect. 2.3.

\subsection{Validation of aerosol optical properties}

The vertical profiles of aerosol optical properties were calculated as reported in Sect. 2.3. In this section, the accuracy of the calculated optical properties is discussed (Sects. 3.2.1 and 3.2.2) before investigating their vertical behavior over the three sampling sites (Sect. 3.3). This discussion is necessary because the reliability of the radiative forcing simulations depends on the robustness of the aerosol optical properties calculation.

Thus, the obtained aerosol optical properties underwent three validation procedures: (1) a columnar comparison of a set of parameters (i.e., refractive index, SSA, AOD, etc.) independently obtained by the Aerosol Robotic Network (AERONET) at 441, 657 and $880 \mathrm{~nm}$ (Sect. 3.2.1); (2) a detailed comparison along vertical profiles between the absorption coefficient measured by the micro-Aeth ${ }^{\circledR}$ AE51 at $880 \mathrm{~nm}$ and the one which was calculated over TR, MI and $\mathrm{ME}$ at the same wavelength (Sect. 3.2.2) and (3) a comparison at ground-level of the absorption coefficient and the Ångström exponent independently obtained using the $7-\lambda$ Aethalometer AE31 (Sect. 3.2.2). This triple validation guarantees the quality of both the columnar-averaged optical parameters and their correct shaping along vertical profiles considering different "validation levels" along vertical profiles: the columnar average, the single data points along vertical profiles and the ground-level values. This procedure was necessary to avoid the presence of compensatory effects along profiles and to perform a right estimation of the radiation absorbed in each atmospheric layer (Sect. 3.4).

In this respect, the comparison with AERONET allowed assuring the reliability of the columnar data and had the advantage to be performed on several wavelengths. The comparison with the micro-Aeth ${ }^{\circledR}$ AE51 data allowed to validate the correct shaping of the optical properties along vertical profiles but it was limited to one wavelength $(880 \mathrm{~nm})$. The comparison with the 7- $\lambda$ Aethalometer AE31 allows validating one point of the profiles (ground level) but on several wavelengths.

Finally, in addition to the validation procedure applied here, the methodology followed to calculate the aerosol optical properties was already validated and published in Ferrero et al. (2011a).

\subsubsection{Columnar validation (comparison with AERONET)}

The quality of the calculated aerosol optical properties was first evaluated along the atmospheric column through a comparison of a set of parameters (i.e., refractive index, SSA, AOD, etc.) independently obtained by the AERONET at 441, 
Table 2. Comparison of the columnar optical and size-distribution properties of the aerosol derived over MI from vertical profile measurements and over AERONET Ispra site $(\sim 57 \mathrm{~km}$ from MI). $n$ and $k$ are the real and imaginary part of the complex refractive index. SSA is the single-scattering albedo. AOD and AOD_Abs are the aerosol optical depth and the absorption aerosol optical depth, respectively. $D_{\mathrm{g}}$ and $\sigma_{\mathrm{g}}$ are the geometric mean diameter and the geometric standard deviation, respectively.

\begin{tabular}{|c|c|c|c|c|c|c|}
\hline \multirow[b]{3}{*}{ Parameter } & \multicolumn{6}{|c|}{ Atmospheric column } \\
\hline & \multicolumn{3}{|c|}{ AERONET - Ispra (235 m) } & \multicolumn{3}{|c|}{ PROFILES - Milano (136 m) } \\
\hline & $441 \mathrm{~nm}$ & $675 \mathrm{~nm}$ & $870 \mathrm{~nm}$ & $441 \mathrm{~nm}$ & $675 \mathrm{~nm}$ & $880 \mathrm{~nm}$ \\
\hline$n$ & $1.415( \pm 0.047)$ & $1.418( \pm 0.046)$ & $1.425( \pm 0.044)$ & $1.501( \pm 0.003)$ & $1.500( \pm 0.004)$ & $1.494( \pm 0.004)$ \\
\hline$k$ & $0.032( \pm 0.009)$ & $0.029( \pm 0.006)$ & $0.030( \pm 0.007)$ & $0.032( \pm 0.003)$ & $0.030( \pm 0.003)$ & $0.030( \pm 0.003)$ \\
\hline SSA & $0.812( \pm 0.028)$ & $0.778( \pm 0.028)$ & $0.740( \pm 0.034)$ & $0.857( \pm 0.013)$ & $0.846( \pm 0.011)$ & $0.812( \pm 0.012)$ \\
\hline AOD & $0.232( \pm 0.091)$ & $0.124( \pm 0.052)$ & $0.083( \pm 0.035)$ & $0.274( \pm 0.046)$ & $0.152( \pm 0.034)$ & $0.092( \pm 0.023)$ \\
\hline AOD_Abs & $0.050( \pm 0.023)$ & $0.032( \pm 0.015)$ & $0.025( \pm 0.012)$ & $0.047( \pm 0.010)$ & $0.028( \pm 0.006)$ & $0.020( \pm 0.005)$ \\
\hline$D_{\mathrm{g}}(\mu \mathrm{m})$ & $0.206( \pm 0.016)$ & $0.206( \pm 0.016)$ & $0.206( \pm 0.016)$ & $0.204( \pm 0.010)$ & $0.204( \pm 0.010)$ & $0.204( \pm 0.010)$ \\
\hline$\sigma_{\mathrm{g}}$ & $1.552( \pm 0.045)$ & $1.552( \pm 0.045)$ & $1.552( \pm 0.045)$ & $1.560( \pm 0.060)$ & $1.560( \pm 0.060)$ & $1.560( \pm 0.060)$ \\
\hline
\end{tabular}

657 and $880 \mathrm{~nm}$ (the only overlapping wavelengths between this study and AERONET). Considering the location of TR, MI and ME, only three AERONET stations were available for this comparison: the Ispra site $\left(45.80^{\circ} \mathrm{N}, 8.63^{\circ} \mathrm{E}\right.$; $235 \mathrm{~m}$ a.s.1.; $57 \mathrm{~km}$ from MI site), the Davos site $\left(46.81^{\circ} \mathrm{N}\right.$, $9.84^{\circ} \mathrm{E} ; 1596 \mathrm{~m}$ a.s.1.; $102 \mathrm{~km}$ and $157 \mathrm{~km}$ from ME and MI sites) and the Bolzano site $\left(46.46^{\circ} \mathrm{N}, 11.33^{\circ} \mathrm{E} ; 262 \mathrm{~m}\right.$ a.s.l.; $25 \mathrm{~km}$ from ME). Unfortunately, the data in Bolzano (during winter 2010) were strongly affected by local dust deposited on the photometer lens (personal communication by the AERONET Bolzano principal investigator, 2012), thus, only the AERONET sites of Ispra and Davos were considered. Their data were compared with those calculated for MI, which was the nearest site. The Ispra site was used for comparison concerning the entire atmospheric column while the Davos site ( 1596 m a.s.l.) for the FT, because of its location at high altitude.

MI data were calculated on statistical mean profiles (Sect. 3.1.1) and we accordingly used the AERONET averaged values from 12 to 25 February as a reference in order to assess the accuracy of our optical estimations. It is necessary to underline that, despite the averaging period is the same, the instantaneous values measured by balloon sounding and by AERONET could not have been coincident and this temporal difference may cause small differences during the comparison.

We start the comparison considering the whole atmospheric column; results are summarized in Table 2 . The average columnar refractive indexes calculated in this study were $1.501( \pm 0.003)+i 0.032( \pm 0.003)$ at $441 \mathrm{~nm}, \quad 1.500( \pm 0.004)+i 0.030( \pm 0.003)$ at $675 \mathrm{~nm}$ and $1.494( \pm 0.004)+i 0.030( \pm 0.003)$ at $880 \mathrm{~nm}$. They were in agreement with the AERONET Ispra estimations: $1.415( \pm 0.047)+i 0.032( \pm 0.009)$ at $441 \mathrm{~nm}$, $1.418( \pm 0.046)+i 0.029( \pm 0.006)$ at $675 \mathrm{~nm}$ and $1.425( \pm 0.044)+i 0.030( \pm 0.007)$ at $870 \mathrm{~nm}$. A slight overestimation of the real part $(+5.6 \pm 0.4 \%)$ was present, while the imaginary part was identical to the measured one.

Instead, results from the sensitivity test (see Sect. 2.3.2) conducted using the density $\left(1.0 \mathrm{~g} \mathrm{~cm}^{-3}\right)$ and the refractive index $(1.75+0.44 i)$ of the OPAC software (Hess et al., 1998) and the density $\left(2.0 \mathrm{~g} \mathrm{~cm}^{-3}\right)$ and the refractive index $(2+1 i)$ reported in Roessler (1984) highlighted a substantial equivalence of the three sets of input parameters in determining the real part of the aerosol refractive index, while the imaginary part experienced an average increase of $+23.5 \pm 3.1 \%$ and $+22.2 \pm 4.6 \%$ (all wavelengths), with respect to AERONET data. This effect was due to the exceedingly low density of the OPAC data (never measured) and to the too high (one of the highest in literature) imaginary part of pure BC reported in Roessler (1984).

The comparison with AERONET validate the use of $\mathrm{BC}$ density and refractive index reported in Bond and Bengstrom (2006) in input to the EMA together with the methodology used for the aerosol refractive index calculation (EMA, $m$ and $\rho$ for pure components, hygroscopic growth) (Sect. 2.3.1). The validation of the refractive index $m$ is crucial as it is at the basis of the optical calculation both during the OPC size-distribution correction and during the Mie calculation (in which the corrected size distribution is itself an important input parameter).

Thus, as a second control, the corrected and interpolated aerosol size distribution was compared with that retrieved by AERONET Ispra: the calculated accumulation mode geometric mean diameter $\left(D_{\mathrm{g}}: 0.204 \pm 0.010 \mu \mathrm{m}\right)$ and the geometric standard deviation $\left(\sigma_{\mathrm{g}}: 1.560 \pm 0.060\right)$ agreed very well with AERONET Ispra $\left(D_{\mathrm{g}}: 0.206 \pm 0.016 \mu \mathrm{m}, \sigma_{\mathrm{g}}\right.$ : $1.552 \pm 0.045$; Table 2) allowing, together with the aforementioned validation of $m$, to accurately estimate the profiles of optical properties using the Mie theory.

The third step was to consider the calculated optical properties along vertical profiles. The calculated SSA $(0.857 \pm$ 0.013 at $441 \mathrm{~nm}, 0.846 \pm 0.011$ at $675 \mathrm{~nm}$ and $0.812 \pm 0.012$ 
at $880 \mathrm{~nm}$ ) was found to be $+8.0 \pm 1.2 \%$ higher than the one derived from AERONET Ispra $(0.812 \pm 0.028$ at $441 \mathrm{~nm}$, $0.778 \pm 0.028$ at $675 \mathrm{~nm}$ and $0.740 \pm 0.034$ at $870 \mathrm{~nm}$ ), similarly for the aerosol optical depth (AOD; Table 2). The absorption optical depth $\left(\mathrm{AOD}_{\mathrm{Abs}}\right.$; Table 2$)$ was instead very close to the AERONET Ispra values. The values of SSA, $\mathrm{AOD}$ and $\mathrm{AOD}_{\mathrm{Abs}}$ are consistent with the slight overestimation of the real part of the refractive index.

From the wavelength dependence of AOD and $\mathrm{AOD}_{\mathrm{Abs}}$ the corresponding columnar Ångström exponents were calculated: 1.56 and 1.24; they were close to the AERONET Ispra estimation: $1.49 \pm 0.12$ and $1.02 \pm 0.07$.

As a further step, the phase function $P(\theta)$ was also validated (as it is required for the aerosol DRE calculation; Sect. 2.4) by comparing it with that estimated by AERONET Ispra. Figure 6a shows this comparison for $\lambda=675 \mathrm{~nm}$; furthermore, a high correlation was found at all the wavelengths $\left(R^{2}=0.988\right)$.

Finally, the FT properties were also investigated comparing data above $1 \mathrm{~km}$ (derived as reported in Sect. 2.2.2), with AERONET Davos data.

Table 3 resumes the results of this comparison underlying that the FT properties were in agreement with the AERONET Davos measurements, especially for what concern the $\mathrm{AOD}_{\mathrm{Abs}}$; the small differences encountered for other parameters (i.e., a slight overestimation of $n:+2.8 \pm 0.9 \%$ ) were considered negligible.

In conclusion, after this comparison, the MI data were considered reliable as they were in good agreement with the columnar AERONET Ispra and Davos data. This result is very important as it validated the procedure used for the optical properties calculation (Sect. 2.3) allowing its application also along the vertical profiles measured over TR and ME as well.

\subsubsection{Vertical profile validation (comparison with Aethalometer data)}

In the previous section, a good agreement between the calculated optical properties and the properties measured by the AERONET network was evidenced.

However, in order to calculate the aerosol DRE at high spatial resolution along vertical profiles (Sect. 2.4) not only a right estimation of the columnar-averaged parameters, but also a correct shaping of them along vertical profiles is needed in order to avoid the presence of compensatory effects along the profiles.

For this purpose, the $b_{\mathrm{abs}}$ measured by the microAeth $^{\circledR}$ AE51 at $880 \mathrm{~nm}$ was compared along vertical profiles with that calculated over TR, MI and ME for the same wavelength (Fig. 6b); results showed an excellent agreement $\left(b_{\text {abs_Mie }}=1.001 \times b_{\text {abs_AE51 }}-0.157, R^{2}=\right.$ $0.996, \mathrm{RMSE}=0.87 \mathrm{Mm}^{-1}$ ) validating the Mie calculation of the $b_{\mathrm{abs}}$ vertical profiles.
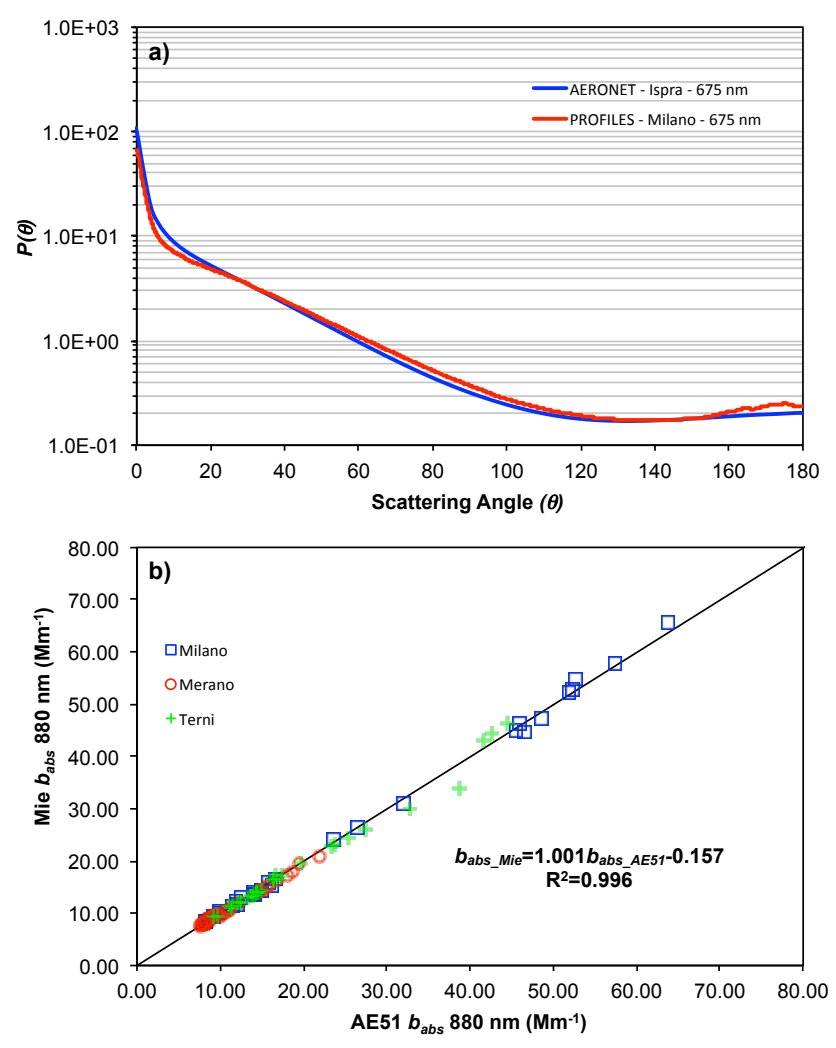

Figure 6. (a) Aerosol phase function $(P(\theta))$ along the atmospheric column over MI and the one obtained at AERONET Ispra; (b) linear correlation between the $b_{\text {abs }}$ determined from Mie calculations and the one measured by the micro-Aeth ${ }^{\circledR}$ AE51 along vertical profiles for TR, MI and ME (the $1: 1$ black line is also plotted).

Moreover, measurements performed close to the ground by the micro-Aeth ${ }^{\circledR}$ AE51 at $880 \mathrm{~nm}$ in ME were compared with that carried out at ground with the $7-\lambda$ Aethalometer AE31 (Sect. 2.2). Only AE31 data that were timely coincident with balloon profiles were considered. The averaged $\mathrm{BC}$ and $b_{\text {abs }}$ measured by the AE51 were $2.75 \pm 0.38 \mu \mathrm{g} \mathrm{m}^{-3}$ and $16.8 \pm 2.3 \mathrm{Mm}^{-1}$ in keeping with the AE31 data: $2.74 \pm$ $0.10 \mu \mathrm{g} \mathrm{m}^{-3}$ and $18.7 \pm 0.7 \mathrm{Mm}^{-1}$, respectively. Moreover, the 7- $\lambda$ AE31 Aethalometer allowed the comparison of the ground-level absorption Ångström exponent $(1.43 \pm 0.03)$ with that obtained by Mie calculation: $1.36 \pm 0.01$.

These results conclude the validation procedure allowing discussing the behavior of both the aerosol optical properties (Sect. 3.3) and of the DRE profiles (Sect. 3.4) over the three sites.

\subsection{Vertical profiles of aerosol optical properties}

The vertical behavior of aerosol optical properties was similar for all the investigated wavelengths; thus, in this section, we report and discuss results at $675 \mathrm{~nm}$, which represent the central wavelength with respect to the wavelength range used for the DRE calculation (Sect. 2.4). In this respect, Fig. 7 
Table 3. Comparison of the free troposphere optical and size-distribution properties of the aerosol derived from OPAC continental-average data and over AERONET Davos site. $n$ and $k$ are the real and imaginary part of the complex refractive index. SSA is the single-scattering albedo. AOD and AOD_Abs are the aerosol optical depth and the absorption aerosol optical depth, respectively. $D_{\mathrm{g}}$ and $\sigma_{\mathrm{g}}$ are the geometric mean diameter and the geometric standard deviation, respectively.

\begin{tabular}{|c|c|c|c|c|c|c|}
\hline \multirow[b]{3}{*}{ Parameter } & \multicolumn{6}{|c|}{ Free troposphere } \\
\hline & \multicolumn{3}{|c|}{ AERONET - Davos (1596 m) } & \multicolumn{3}{|c|}{ PROFILES - FT (> 1000 m) } \\
\hline & $438 \mathrm{~nm}$ & $676 \mathrm{~nm}$ & $870 \mathrm{~nm}$ & $441 \mathrm{~nm}$ & $675 \mathrm{~nm}$ & $880 \mathrm{~nm}$ \\
\hline$n$ & $1.449( \pm 0.009)$ & $1.468( \pm 0.010)$ & $1.482( \pm 0.010)$ & $1.511( \pm 0.006)$ & $1.510( \pm 0.006)$ & $1.501( \pm 0.006)$ \\
\hline$k$ & $0.010( \pm 0.004)$ & $0.010( \pm 0.005)$ & $0.011( \pm 0.005)$ & $0.011( \pm 0.001)$ & $0.011( \pm 0.001)$ & $0.011( \pm 0.001)$ \\
\hline SSA & $0.950( \pm 0.018)$ & $0.947( \pm 0.020)$ & $0.941( \pm 0.023)$ & $0.955( \pm 0.002)$ & $0.932( \pm 0.003)$ & $0.897( \pm 0.004)$ \\
\hline AOD & $0.036( \pm 0.004)$ & $0.022( \pm 0.002)$ & $0.015( \pm 0.001)$ & $0.039( \pm 0.002)$ & $0.014( \pm 0.001)$ & $0.006( \pm 0.001)$ \\
\hline AOD_Abs & $0.002\left( \pm 5 \times 10^{-4}\right)$ & $0.001\left( \pm 4 \times 10^{-4}\right)$ & $0.001\left( \pm 3 \times 10^{-4}\right)$ & $0.002\left( \pm 6 \times 10^{-5}\right)$ & $0.001\left( \pm 4 \times 10^{-5}\right)$ & $0.001\left( \pm 3 \times 10^{-5}\right)$ \\
\hline$D_{\mathrm{g}}(\mu \mathrm{m})$ & $0.269( \pm 0.011)$ & $0.269( \pm 0.011)$ & $0.269( \pm 0.011)$ & $0.299( \pm 0.001)$ & $0.299( \pm 0.001)$ & $0.299( \pm 0.001)$ \\
\hline$\sigma_{\mathrm{g}}$ & $1.637( \pm 0.024)$ & $1.637( \pm 0.024)$ & $1.637( \pm 0.024)$ & $1.111( \pm 0.001)$ & $1.111( \pm 0.001)$ & $1.111( \pm 0.001)$ \\
\hline
\end{tabular}
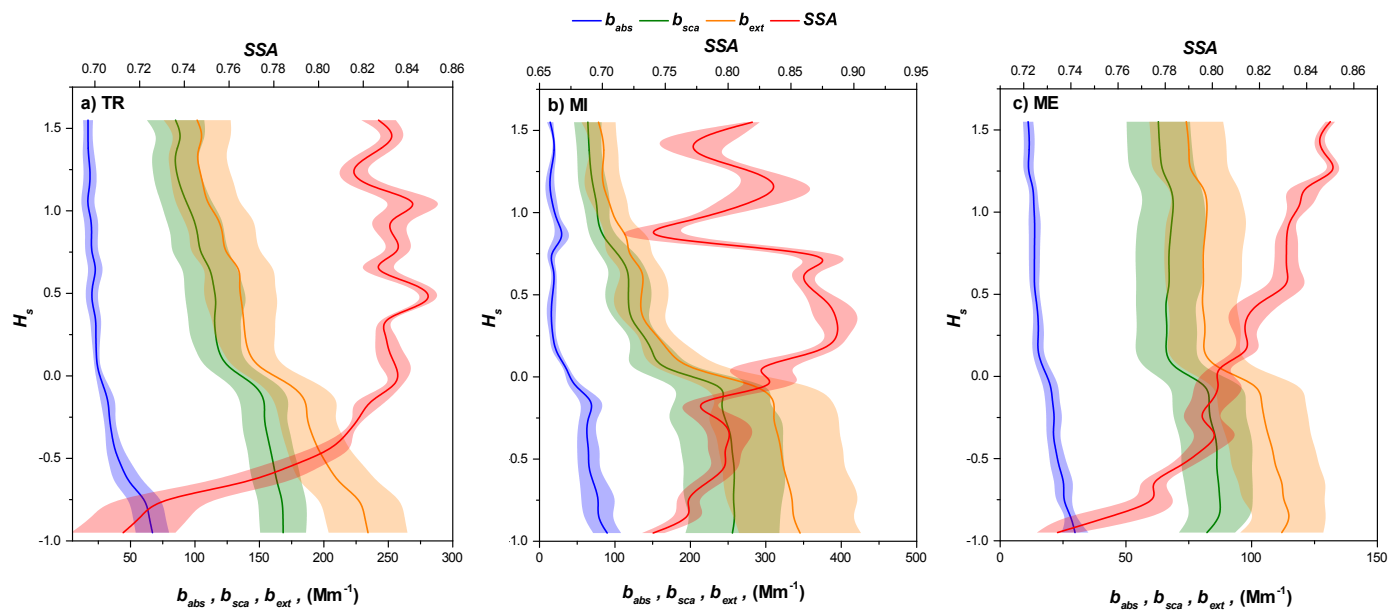

Figure 7. Vertical profiles of aerosol optical properties $\left(b_{\mathrm{abs}}, b_{\mathrm{sca}}, b_{\mathrm{ext}}\right.$ and SSA) at $675 \mathrm{~nm}$ over (a) TR, (b) MI and (c) ME.

shows the vertical profiles of the aerosol optical properties (at $675 \mathrm{~nm}$ ) over TR, MI and ME; from this figure, it is possible to observe first the analogy with Fig. 4, where vertical profiles of $\mathrm{BC}$ and aerosol concentration are reported. Thus, the observed behavior of optical properties is here discussed addressing the vertical changes of the aerosol physicochemical properties reported in Sect. 3.1.

The most evident behavior of aerosol optical properties is related to the observed changes across the $\mathrm{MH}\left(H_{\mathrm{s}}=0\right)$, where $b_{\text {sca }}$ and $b_{\text {abs }}$ decreased strongly going from BMH to AMH. On average $b_{\text {sca }}$ and $b_{\text {abs }}$ decreased (from $\mathrm{BMH}$ to $\mathrm{AMH}$ ) over TR by $-43.1 \pm 3.0 \%$ (from $157.6 \pm 2.3$ to $89.7 \pm 4.5 \mathrm{Mm}^{-1}$ for $b_{\text {sca }}$ ) and by $-58.8 \pm 4.5 \%$ (from $45.3 \pm 4.6$ to $18.7 \pm 0.7 \mathrm{Mm}^{-1}$ for $\left.b_{\mathrm{abs}}\right)$. Over MI their decrease was of $-61.2 \pm 3.1 \%$ (from $253.3 \pm 2.0$ to $98.2 \pm$ $7.7 \mathrm{Mm}^{-1}$ for $b_{\text {sca }}$ ) and of $-71.3 \pm 3.0 \%$ (from $69.0 \pm 4.0$ to $19.8 \pm 1.7 \mathrm{Mm}^{-1}$ for $b_{\text {abs }}$ ) while over ME the decrease was of $-23.5 \pm 0.8 \%$ (from $85.1 \pm 0.7$ to $65.1 \pm 0.4 \mathrm{Mm}^{-1}$ for $b_{\text {sca }}$ ) and of $-47.6 \pm 2.5 \%$ (from $23.8 \pm 1.0$ to $12.4 \pm$ $0.2 \mathrm{Mm}^{-1}$ for $\left.b_{\mathrm{abs}}\right)$. Thus, in the lower troposphere the $\mathrm{MH}$ becomes also crucial not only to understand the aerosol pollution, but also to shape the vertical behavior of the aerosol optical properties (Sect. 3.1.1 and Fig. 4). In this respect, the most important result that can be observed from the previous findings is the higher (percentage) decrease of $b_{\mathrm{abs}}$ across the $\mathrm{MH}$ than that of $b_{\text {sca. }}$. As a consequence, the SSA increased along height (from BMH to AMH) over the three sites by $+5.7 \pm 2.0 \%$ over TR (from $0.781 \pm 0.014$ to $0.825 \pm 0.004),+4.9 \pm 2.2 \%$ over MI (from $0.787 \pm 0.010$ to $0.826 \pm 0.014$ ) and by $+7.4 \pm 1.0 \%$ over ME (from $0.783 \pm 0.007$ to $0.840 \pm 0.002$ ). The SSA increase with height, across the MH, is of a great importance as, first, it appears as a general behavior over the three investigated sites and, second, this behavior affects the aerosol DRE and the heating rate as it will be discussed in Sect. 3.4. This result is in agreement with the decrease of the aerosol BC content over the three sites, as highlighted in Sect. 3.1.1, Figs. 4 and 5 , where it was evidenced that $\mathrm{AMH}$ the $\mathrm{BC}$ aerosol fraction decreased and a corresponding increase in scattering species (i.e., ionic compounds) was present. 

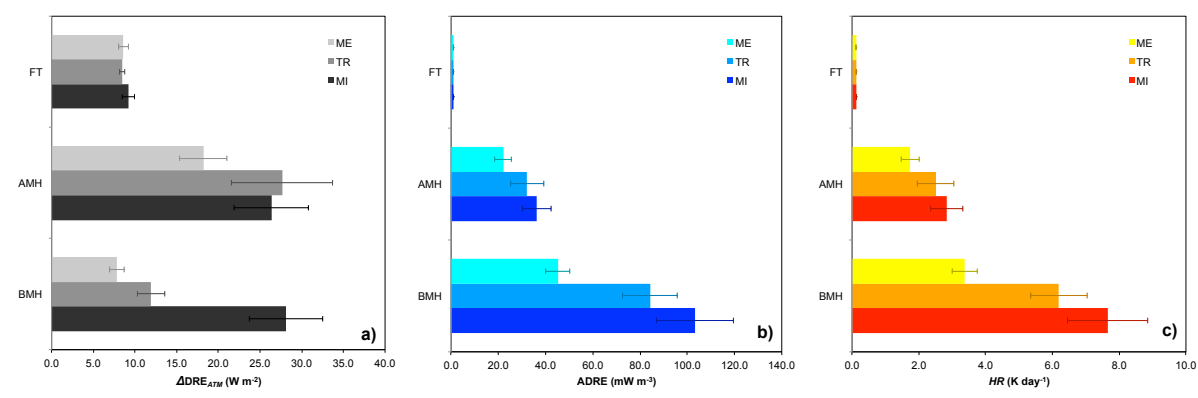

Figure 8. $\triangle \mathrm{DRE}_{\mathrm{ATM}}(\mathbf{a}), \mathrm{ADRE}$ (b) and HR (c) calculated for each site and broad-range altitude layers: $\mathrm{BMH}$ (from ground to MH), AMH (from $\mathrm{MH}$ to $1 \mathrm{~km}$ ) and $\mathrm{FT}(>1 \mathrm{~km})$.

Figure 7 also highlighted that, $\mathrm{BMH}$, the highest values of $b_{\text {sca }}$ and $b_{\text {abs }}$ were observed in MI, followed by TR and then by ME, thus reflecting the pollution level over the three sites as described in Sect. 3.1.1. Moreover, the highest values of $b_{\mathrm{abs}}$ were found close to the ground (within the first 50-100 m), as happened for BC (compare Fig. 4), resulting in an average increase of $+44.9 \%$ over TR, of $+19.8 \%$ over MI and of $+21.9 \%$ over ME, compared to the average $b_{\text {abs }}$ values found BMH. On the contrary, a similar behavior of $b_{\text {sca }}$ was not observed. Consequently, the SSA reached its minimum value close to ground decreasing (compared to the average found $\mathrm{BMH}$ ) of $-8.2 \%$ over TR, of $-3.8 \%$ over MI and of $-4.7 \%$ over ME. This behavior increased again the heating-rate effect of aerosol in proximity of the ground (Sect. 3.4). The influence of the aerosol physicochemical properties on the optical ones was also highlighted by the coefficients of variation of $\mathrm{BC}$, aerosol concentration, $b_{\mathrm{abs}}$, $b_{\text {sca }}$ and $b_{\text {ext }}$ (resumed in Table S1 in the Supplement) that showed a good agreement among themselves for both BMH and AMH data.

Finally, as the DRE calculations (Sect. 2.4) require the FT aerosol optical properties as input data (the FT validation has been already discussed in Sect. 3.2.1; Table 3), we report here their values. $b_{\text {sca }}$ and $b_{\text {abs }}$ were $1.9 \pm 0.9$ and $0.2 \pm$ $0.1 \mathrm{Mm}^{-1}$, respectively; the FT SSA was $0.932 \pm 0.003$, higher than the values AMH. This observation, expected due to the decreasing $\mathrm{BC}$ content with height, highlighted again that the most absorptive aerosol was located in the lower atmospheric layers, BMH and close to the ground.

\subsection{DRE and heating-rate profiles}

As illustrated in the previous section, the aerosol optical properties drastically changed along height over the three sites. They were used as input to calculate the vertical profiles of the instantaneous aerosol DRE over TR, MI and ME at noon (Sect. 2.4).

The vertical profiles of aerosol DRE are reported in Fig. S1 in the Supplement. They showed the high level of the dimming effect induced by the aerosol at the surface: the highest DRE was observed over MI $\left(-69.3 \pm 8.8 \mathrm{~W} \mathrm{~m}^{-2}\right)$ followed by TR $\left(-54.4 \pm 7.7 \mathrm{~W} \mathrm{~m}^{-2}\right)$ and by ME $(-40.7 \pm$ $3.7 \mathrm{~W} \mathrm{~m}^{-2}$ ). Results were in keeping with the aerosol and $\mathrm{BC}$ concentrations, and with the optical properties reported in Figs. 4 and in 7, respectively. At the top of atmosphere, the DRE was similar among the three sites: $-5.6 \pm 0.7 \mathrm{~W} \mathrm{~m}^{-2}$ (MI), $-6.3 \pm 0.3 \mathrm{~W} \mathrm{~m}^{-2}$ (TR) and $-6.1 \pm 0.6 \mathrm{~W} \mathrm{~m}^{-2}$ (ME). The aforementioned data were in keeping with values reported in literature (Perrone and Bergamo, 2011; Saha et al., 2008; Chakrabarty et al., 2012).

These data indicated a net columnar cooling effect of the aerosol on the Earth-atmospheric system. However, the difference between the DRE at the top and the bottom of the atmosphere indicated that a significant amount of energy was absorbed into the atmosphere thus heating it.

In order to quantify this phenomenon, the difference between the DRE at the top and the bottom of each atmospheric layer $\left(\triangle D_{R E} E_{A T M}\right)$ was first calculated using Eq. (13) (Sect. 2.4) for each site and broad-range altitude layers: $\mathrm{BMH}$ (from ground to $\mathrm{MH}$ ), AMH (from $\mathrm{MH}$ to $1 \mathrm{~km}$ ), FT $(>1 \mathrm{~km})$ (compare Sect. 2.2.2). Results are reported in Fig. 8a; they highlighted a generally high level of atmospheric absorption both BMH $\left(\triangle \mathrm{DRE}_{\mathrm{ATM}}: 11.9 \pm 1.6\right.$, $28.1 \pm 4.4$ and $7.8 \pm 0.9 \mathrm{~W} \mathrm{~m}^{-2}$ over TR, MI and ME) and $\mathrm{AMH}\left(\triangle \mathrm{DRE}_{\mathrm{ATM}}: 27.7 \pm 6.1,26.4 \pm 4.5\right.$ and $18.2 \pm$ $2.8 \mathrm{~W} \mathrm{~m}^{-2}$ over TR, MI and ME) compared to the FT $\left(\triangle \mathrm{DRE}_{\mathrm{ATM}}: 8.5 \pm 0.3,9.2 \pm 0.7\right.$ and $8.6 \pm 0.6 \mathrm{~W} \mathrm{~m}^{-2}$ over TR, MI and ME). As a result, the atmospheric absorption took place mainly within the first $\mathrm{km}$ of the atmosphere $(\mathrm{BMH}+\mathrm{AMH})$, with a percentage (compared to the whole atmosphere) of $82.4,85.5$ and $75.1 \%$ over TR, MI and $\mathrm{ME}$, respectively; the high aerosol pollution level below and strictly above the MH (Sect. 3.1) was responsible of this macroscopic behavior.

However, as stated in Sect. 2.4, $\Delta \mathrm{DRE}_{\mathrm{ATM}}$ quantifies the integrated radiative power density absorbed by the aerosol within each atmospheric layer. Therefore, the aforementioned $\triangle \mathrm{DRE}_{\mathrm{ATM}}$ data did not allow comparing the atmospheric absorption both among the three sites and, within each site, along the atmospheric column. The main reasons are the different MH found over TR, MI and ME (142 \pm 22 , $272 \pm 50$ and $173 \pm 42 \mathrm{~m}$, respectively; Sect. 3.1.1) and the 

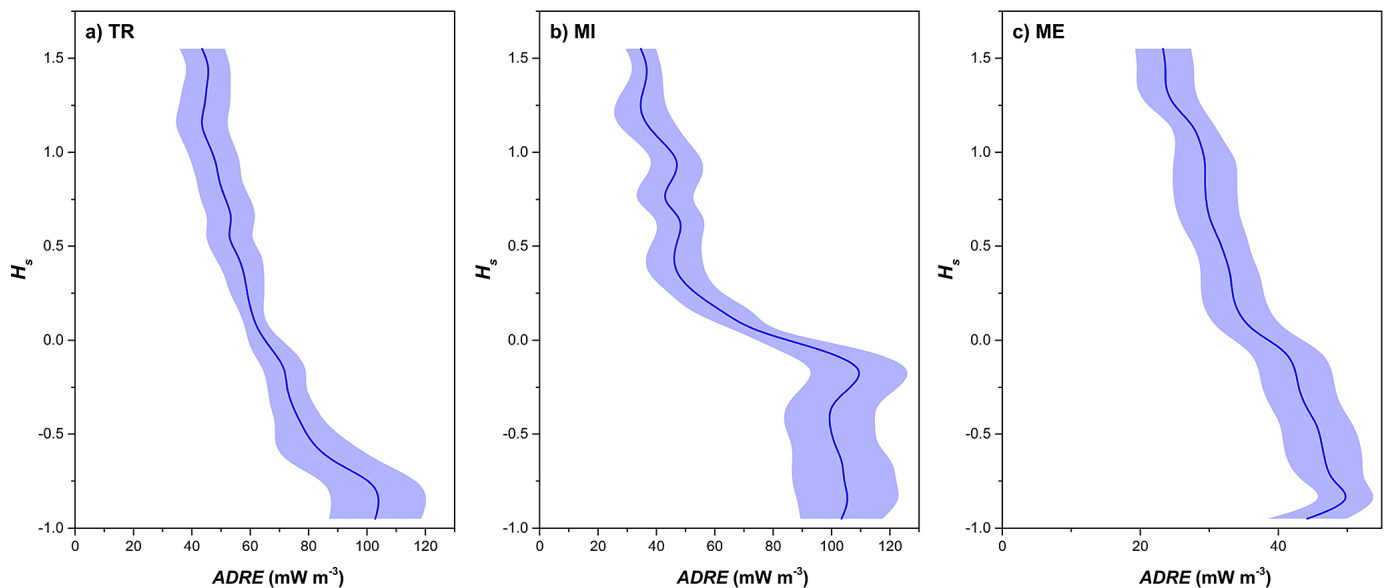

Figure 9. Continuous vertical profiles of ADRE over TR (a), MI (b) and ME (c).
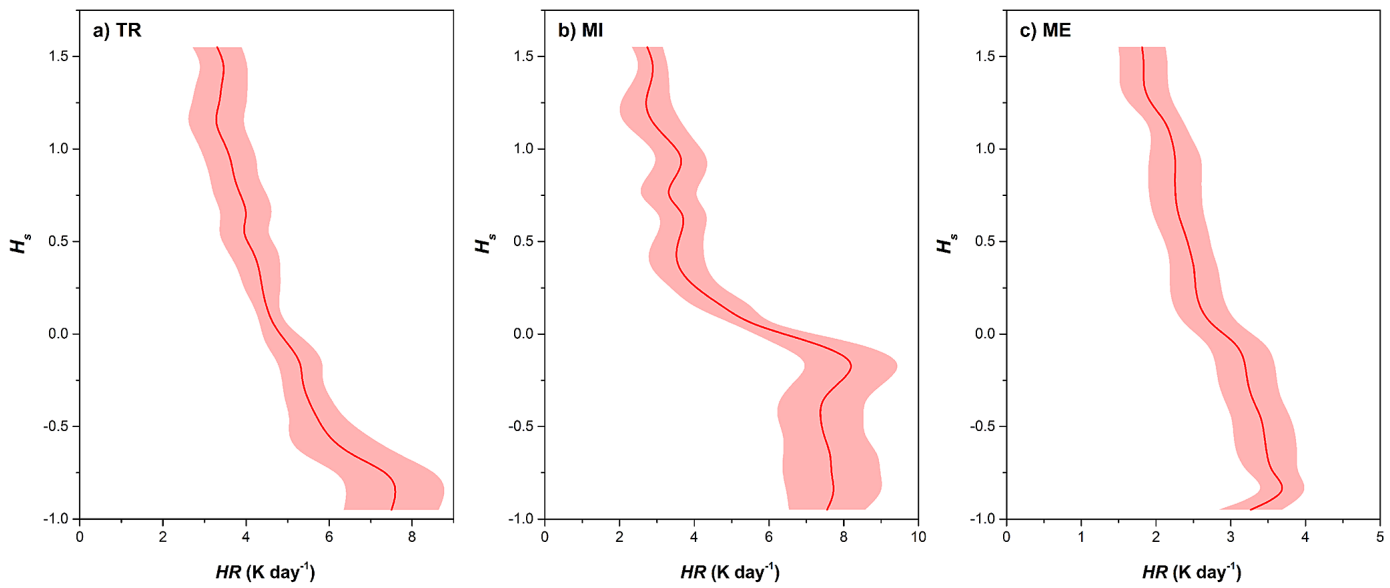

Figure 10. Continuous vertical profiles of HR over TR (a), MI (b) and ME (c).

broader altitude range of the FT compared to the BMH and AMH layers.

Thus, in order to describe and compare the vertical behavior of atmospheric absorption in different situations, the absorptive DRE (ADRE, Sect. 2.4) was calculated accordingly to Eq. (14) normalizing $\triangle \mathrm{DRE}_{\mathrm{ATM}}$ by the thickness of each layer; since the wintertime aerosol absorption was mainly due to the presence of BC (compare Sect. 3.3), the ADRE represented, in first approximation, the atmospheric DRE induced by BC.

ADRE values for each site and broad-range altitude layers (BMH, AMH and FT) are reported in Fig. 8b. By excluding the effect of the layer thickness, it is now possible to realize that the most intense atmospheric absorption was observed BMH, particularly over MI (103.3 \pm $\left.16.2 \mathrm{~mW} \mathrm{~m}^{-3}\right)$ followed by TR $\left(84.3 \pm 11.5 \mathrm{~mW} \mathrm{~m}^{-3}\right)$ and by $\mathrm{ME}\left(45.2 \pm 5.1 \mathrm{~mW} \mathrm{~m}^{-3}\right)$; the same order was observed considering AMH data: higher values were found over MI $\left(36.2 \pm 6.2 \mathrm{~mW} \mathrm{~m}^{-3}\right)$ followed by TR $\left(32.2 \pm 7.1 \mathrm{~mW} \mathrm{~m}^{-3}\right)$ and ME $\left(22.0 \pm 3.4 \mathrm{~mW} \mathrm{~m}^{-3}\right)$. Finally, the FT experienced the lower absorption: $0.9 \pm 0.1 \mathrm{~mW} \mathrm{~m}^{-3}$ over the three sites.

Interestingly, these data evidenced an average decrease of ADRE across the MH of $-64.9 \pm 0.6 \%$ over MI, of $-61.8 \pm 3.2 \%$ over TR and of $-51.3 \pm 2.0 \%$ over ME, in keeping with the vertical behavior of both $\mathrm{BC}$ and $b_{\mathrm{abs}}$ (Sects. 3.1.1 and 3.3). Also the continuous ADRE vertical profiles (Fig. 9) are in agreement with data shown in Figs. 4 and 7. Thus, despite the absolute values, a common feature occurred over MI, TR, and ME as a sharp decrease of the ADRE was observed at the MH $\left(H_{\mathrm{s}}=0\right)$. Most of the ADRE occurred within the mixing layer, in agreement with the $\mathrm{BC}$ pollution loading in basin valleys, especially over the most urbanized and industrialized sites of MI and TR.

This behavior has an important feature, as the ADRE induces an instantaneous HR that was computed following Eq. (16) (Sect. 2.4). The calculated HR values are reported in Fig. 8c (for BMH, AMH and FT). The highest degree of instantaneous heating rate was observed $\mathrm{BMH}$ : $7.7 \pm$ $1.2 \mathrm{~K} \mathrm{day}^{-1}$ over MI, $6.2 \pm 0.8 \mathrm{~K} \mathrm{day}^{-1}$ over TR and $3.4 \pm$ 
$0.4 \mathrm{~K} \mathrm{day}^{-1}$ over ME. Above the MH values were lower, but the same order was observed: higher values were found over MI $\left(2.8 \pm 0.5 \mathrm{~K} \mathrm{day}^{-1}\right)$ followed by TR $\left(2.5 \pm 0.5 \mathrm{~K} \mathrm{day}^{-1}\right)$ and by $\mathrm{ME}\left(1.7 \pm 0.3 \mathrm{~K}_{\text {day }}{ }^{-1}\right)$. Finally, in the FT the HR was the lowest over the three sites: $0.1 \pm 1 \times 10^{-2} \mathrm{~K}_{\text {day }}{ }^{-1}$.

These results are very important, as in literature vertical profiles of HR are few and usually only the average columnar HR is estimated. For example, Chakrabarty et al. (2012) estimated a columnar average $\mathrm{HR}$ of $\sim 2 \mathrm{~K}$ day $^{-1}$ considering a $\Delta p$ of $300 \mathrm{hPa}$; as a comparison, using the same approach over TR, MI and ME, the average columnar HR was $\sim 1-2 \mathrm{~K} \mathrm{day}^{-1}$ in agreement with that study.

However, the estimation of the average columnar HR could be misleading as it does not give any information regarding where the HR is located and which feedbacks can trigger.

In the present work, due to the high vertical resolution of balloon soundings, a step forward can be done as the heating dynamics across the MH was well characterized. In this respect, continuous HR profiles are reported in Fig. 10 and showed (together with Fig. 8c) that most of the HR occurred within the mixing layer and that a strong vertical gradient was present at the MH, in agreement with ADRE (Figs. 8b and 9). This happened over TR, MI and ME, pointing towards a common behavior over basin valleys, where stagnant atmospheric conditions are present (Sect. 3.1.1 and Fig. 2).

As the vertical behavior of the HR can trigger different feedbacks able to promote the aerosol semi-direct effect (IPCC, 2013), it is interesting to note (Fig. 10) that the highest $\mathrm{HR}$ values were observed $\mathrm{BMH}$ and that they could turn into a weakening of the ground-based thermal inversion, which are common in basin valleys (Ferrero et al., 2012).

Consequently, it would be helpful to "describe" the vertical behavior of the HR in terms of the potential feedbacks that it could promote using a simple parameter. Here we propose the use of the heating rate vertical gradient $\left(\mathrm{K} \mathrm{day}^{-1} \mathrm{~km}^{-1}\right)$ as a proxy of the feedback potential (HERFPO: heating rate feedback potential). The HERFPO represents the atmospheric thermal lapse rate that would take place if the forcing induced by the instantaneous HR profile would last all day.

Thus, the HERFPO was calculated along the HR profiles (from the bottom to the top) over each measuring site obtaining the following values: $-8.3 \pm 1.2 \mathrm{~K} \mathrm{day}^{-1} \mathrm{~km}^{-1}$ over MI, $-6.1 \pm 0.5 \mathrm{~K} \mathrm{day}^{-1} \mathrm{~km}^{-1}$ over TR and $-2.6 \pm$ $0.2 \mathrm{~K} \mathrm{day}^{-1} \mathrm{~km}^{-1}$ over ME.

The comparison of these data with the atmospheric dry adiabatic lapse rate $\left(-10 \mathrm{~K} \mathrm{~km}^{-1}\right)$ suggested that the vertical HR had really the potential to result in a negative feedback promoting an increase of the atmospheric dispersal conditions, by weakening the ground-based thermal inversions, especially over MI and TR. However, it is of great importance to consider that HERFPO refers only the to the behavior of the atmosphere. Hence, in order to fully understand the feedback induced by the aerosol and $\mathrm{BC}$ on the atmospheric turbulence, the energy fluxes between ground and the atmosphere have also to be considered. In this respect, the high level of dimming induced by aerosol at the surface (as shown at the beginning of this section) could balance the atmospheric effect of HERFPO.

In conclusion, in the context of future applications of this concept and of the aforementioned results, the role of each parameter in determining atmospheric feedbacks, as well as their net effect, has to be considered and investigated.

\section{Conclusions}

Vertical profiles of BC and aerosol number-size distribution were measured over three Italian basin valleys (Terni Valley, Po Valley and Passiria valleys) allowing the characterization of the aerosol and $\mathrm{BC}$ dispersion under similar orographic conditions. Changes of BC concentrations and of aerosol BC fraction as a function of the height were related with variations of aerosol optical properties, radiative forcing and heating rate.

Measurements were conducted during three week-long wintertime campaigns. The aerosol vertical profiles have been determined by means of a tethered balloon-based moving platform (fitted with a micro-Aethalometer, an OPC, a cascade impactor and a meteorological station) while the aerosol chemical composition was determined analyzing $\mathrm{PM}_{2.5}$ samples collected at different heights.

Results from the measured vertical profiles allowed to clearly identify the mixing height $(\mathrm{MH})$, which was characterized by a strong vertical concentration gradient of both BC (range: from $-48.4 \pm 5.3$ to $-69.1 \pm 5.5 \%$ ) and aerosol (range: form $-23.9 \pm 4.3$ to $-46.5 \pm 7.3 \%$ ). Above the $\mathrm{MH}$, not only the $\mathrm{BC}$ concentration, but also its aerosol fraction decreased (range: from $-33.2 \pm 4.9$ to $-47.5 \pm 7.9 \%$ ) while a shallow BC layer of higher concentrations (range: from +16.1 to $+34.2 \%$ ) was found close to the ground, in the first $50-100 \mathrm{~m}$ of the atmosphere, due to the proximity of BC sources.

These behaviors caused important changes of the optical properties of the aerosol $\left(b_{\mathrm{abs}}, b_{\mathrm{sca}}, b_{\mathrm{ext}}\right.$, SSA) at different heights that were quantified applying Mie theory to aerosol data. Before this step, the aerosol refractive index was calculated using the effective medium approximation applied to aerosol chemical composition and the OPC number-size distribution was corrected for the ambient aerosol refractive index and log-normally interpolated. Results were validated with AERONET data and evidenced an increase of the single-scattering albedo with height (range: from $+4.9 \pm 2.2$ to $+7.4 \pm 1.0 \%$ ).

The effect of optical properties changes with height was assessed using a radiative transfer model (libRadtran) from which vertical profiles of direct aerosol radiative forcing, atmospheric absorption and heating rate were calculated. In order to study the radiative power absorbed into the 
atmosphere along continuous vertical profiles, a new parameter, the absorptive direct radiative effect (ADRE) was developed normalizing the radiative power density absorbed into each atmospheric layer by the layer height. The highest atmospheric absorption (ADRE) was observed below the mixing height (range: from $+45.2 \pm 5.1$ to $+103.3 \pm$ $16.2 \mathrm{~mW} \mathrm{~m}^{-3}$ ) influencing the heating-rate profile. Hence, the heating rate vertical gradient $\left(\mathrm{K} \mathrm{day}^{-1} \mathrm{~km}^{-1}\right)$ was investigated allowing to estimate the heating rate feedback potential (HERFPO). The HERFPO ranged from $-2.6 \pm 0.2$ to $-8.3 \pm 1.2 \mathrm{~K} \mathrm{day}^{-1} \mathrm{~km}^{-1}$. Thus, the behavior of BC loaded below the $\mathrm{MH}$ promoted a negative feedback favorable to the increase of the atmospheric dispersal conditions.
The obtained results were similar over the three sites and pointed towards a common aerosol dynamics over basin valleys characterized by comparable atmospheric stagnant conditions. These data represent the first high-resolution vertical profile of aerosol radiative forcing and heating rate obtained over Italy and Europe and allowed to describe with a great vertical detail the radiative forcing induced by BC (and aerosol) in the lower troposphere, across the mixing layer and within it, where the anthroposphere is located. 


\section{Appendix A}

Table A1. Acronyms.

\begin{tabular}{ll}
\hline ADRE & Absorptive direct radiative effect \\
AERONET & Aerosol Robotic Network \\
a.g.l. & Above ground level \\
AMH & Above mixing height \\
ASL & Above sea level \\
ATN & light attenuation \\
BC & Black carbon \\
BMH & Below mixing height \\
BR & Bruggeman \\
CMG & Climate modeling grid \\
DRE & Direct radiative effect \\
DRH & Deliquescence relative humidity \\
EMA & Effective medium approximation \\
FT & Free troposphere \\
HERFPO & Heating rate feedback potential \\
HR & Heating rate \\
LL & Lorentz-Lorenz \\
ME & Merano \\
MG & Maxwell-Garnett \\
MH & Mixing height \\
MI & Milan \\
MODIS & Moderate resolution imaging spectroradiometer \\
OM & Organic Matter \\
OPC & Optical particle counter \\
PLS & Polystyrene latex spheres \\
RH & Relative humidity \\
RTM & Radiative transfer model \\
SSA & Single-scattering albedo \\
$T$ & Temperature \\
TOA & Top of atmosphere \\
TR & Terni \\
WINSOM & Water-insoluble OM \\
WSOM & Water-soluble OM \\
\hline &
\end{tabular}




\section{The Supplement related to this article is available online at doi:10.5194/acp-14-9641-2014-supplement.}

Acknowledgements. We thank Fondazione CARIT di Terni e Narni, ARPA Umbria, EURAC and the SINOPIAE project (funded by Lombardy Region) for financial support to this research. We are grateful to the physical and chemical laboratory of the autonomous province of Bolzano-Bozen for the logistic support during the campaign in Merano. Finally, we thank both Giuseppe Zibordi and Christoph Wehrli for their effort in establishing and maintaining the AERONET Ispra and Davos sites, respectively.

Edited by: H. Saathoff

\section{References}

Ackerman, T. P. and Toon, O. B.: Absorption of visible radiation in atmosphere containing mixtures of absorbing and nonabsorbing particles, Appl. Optics, 20, 3661-3668, 1981.

Anderson, G. P., Clough, S. A., Kneizys, F. X., Chetwynd, J. H., and Shettle, E. P.: AFGL Atmospheric Constituent Profiles $(0.120 \mathrm{~km})$, Air Force Geophysics Lab Hanscom AFB MA, ADA175173, available at: http://oai.dtic.mil/oai/oai?verb= getRecord\&metadataPrefix $=$ html\&identifier=ADA175173 (last access: 11 September 2014), 1986.

Angelini, F., Barnaba, F., Landi, T. C., Caporaso, L., and Gobbi, G. P.: Study of atmospheric aerosols and mixing layer by lidar, Radiat. Prot. Dosim., 137, 275-279, 2009.

Arnott, W. P., Hamasha, K., Moosmüller, H., Sheridan, P. J., and Ogren, J. A.: Towards Aerosol Light-Absorption Measurements with a 7-Wavelength Aethalometer: Evaluation with a Photoacoustic Instrument and 3-Wavelength Nephelometer, Aerosol Sci. Tech., 39, 17-29, doi:10.1080/027868290901972, 2005.

Aspnes, D. E.: Local-field effects and effective medium theory: A microscopic perspective, Am. J. Phys., 50, 704-709, 1982.

Babu, S. S., Sreekanth, V., Moorthy, K. K., Mohan, M., Kirankumar, N. V. P., Subrahamanyam, D. B., Gogoi, M. M., Kompalli, S. K., Beegum, N., Chaubey, J. P., Kumar, V. H. A., and Manchanda, R. K.: Vertical profiles of aerosol black carbon in the atmospheric boundary layer over a tropical coastal station: Perturbations during an annular solar eclipse, Atmos. Res., 99, 471478, doi:10.1016/j.atmosres.2010.11.019, 2011.

Baron, P. A. and Willeke, K.: Aerosol measurements, Principles, Techniques and Applications, Wiley-Interscience, 2nd Edn., 2005.

Bohren, C. F. and Huffman, D. R.: Absorption and Scattering of Light by Small Particles, John Wiley, New York, NY, 1983.

Bond, T. C. and Bergstrom, R. W.: Light Absorption by Carbonaceous Particles: An Investigative Review, Aerosol Sci. Tech., 40, 27-67, doi:10.1080/02786820500421521, 2006.

Bond, T. C., Doherty, S. J., Fahey, D. W., Forster, P. M., Berntsen, T., Deangelo, B. J., Flanner, M. G., Ghan, S., Kärcher, B., Koch, D., Kinne, S., Kondo, Y., and Quinn, P. K.: Bounding the role of black carbon in the climate system?: A scientific assessment, J. Geophys. Res., 118, 1-173, doi:10.1002/jgrd.50171, 2013.
Bruggeman, D.: Calculation of various physics constants in heterogenous substances. I. Dielectricity constants and conductivity of mixed bodies from isotropic substances, Ann. Phys.-Berlin, 24, 636-664, 1935.

Cahill, J. F., Suski, K., Seinfeld, J. H., Zaveri, R. A., and Prather, K. A.: The mixing state of carbonaceous aerosol particles in northern and southern California measured during CARES and CalNex 2010, Atmos. Chem. Phys., 12, 10989-11002, doi:10.5194/acp-12-10989-2012, 2012.

Cape, J. N., Coyle, M., and Dumitrean, P.: The atmospheric lifetime of black carbon, Atmos. Environ., 59, 256-263, doi:10.1016/j.atmosenv.2012.05.030, 2012.

Carbone, C., Decesari, S., Mircea, M., Giulianelli, L., Finessi, E., Rinaldi, M., Fuzzi, S., Marinoni, A., Duchi, R., Perrino, C., Sargolini, T., Vardè, M., Sprovieri, F., Gobbi, G. P., Angelini, F., and Facchini, M. C.: Size-resolved aerosol chemical composition over the Italian Peninsula during typical summer and winter conditions, Atmos. Environ., 44, 5269-5278, doi:10.1016/j.atmosenv.2010.08.008, 2010.

Chakrabarty, R. K., Garro, M. A., Wilcox, E. M., and Moosmüller, H.: Strong radiative heating due to wintertime black carbon aerosols in the Brahmaputra River Valley, Geophys. Res. Lett., 39, L09804, doi:10.1029/2012GL051148, 2012.

Chazette, P. and Liousse, C.: A case study of optical and chemical ground apportionment for urban aerosols in Thessaloniki, Atmos. Environ., 35, 2497-2506, doi:10.1016/S13522310(00)00425-8, 2001.

Chýlek, P., Videen, G., Ngo, D., Pinnick, R., and Klett, J.: Effect of black carbon on the optical-properties and climate forcing of sulfate aerosols, J. Geophys. Res., 100, 16325-16332, 1995.

Clegg, S. L., Brimblecombe, P., and Wexler, A. S.: Thermodynamic Model of the System $\mathrm{H}^{+}-\mathrm{NH}_{4}^{+}-\mathrm{SO}_{4}^{2-}-\mathrm{NO}_{3}-\mathrm{H}_{2} \mathrm{O}$ at Tropospheric Temperatures, J. Phys. Chem. A, 102, 2137-2154, 1998.

Corrigan, C. E., Roberts, G. C., Ramana, M. V., Kim, D., and Ramanathan, V.: Capturing vertical profiles of aerosols and black carbon over the Indian Ocean using autonomous unmanned aerial vehicles, Atmos. Chem. Phys., 8, 737-747, doi:10.5194/acp-8-737-2008, 2008.

Crosbie, A. L. and Davidson, G. W.: Dirac-Delta approximations to the scattering phase function, J. Quant. Spectrosc. Ra., 33, 391409, 1985.

Das, S. K. and Jayaraman, A.: Role of black carbon in aerosol properties and radiative forcing over western India during premonsoon period, Atmos. Res., 102, 320-334, 2011.

Deshler, T.: Thirty years of in situ stratospheric aerosol size distribution measurements from Laramie, Wyoming $\left(41^{\circ} \mathrm{N}\right)$, using balloon-borne instruments, J. Geophys. Res., 108, 4167, doi:10.1029/2002JD002514, 2003.

Di Nicolantonio, W., Cacciari, A., Petritoli, A., Carnevale, C., Pisoni, E., Volta, M. L., Stocchi, P., Curci, G., Bolzacchini, E., Ferrero, L., Ananasso, C., and Tomasi, C.: MODIS and OMI satellite observations supporting air quality monitoring, Radiat. Prot. Dosim., 137, 280-287, 2009.

Emili, E., Popp, C., Petitta, M., Riffler, M., Wunderle, S., and Zebisch, M.: PM10 remote sensing from geostationary SEVIRI and polar-orbiting MODIS sensors over the complex terrain of the European Alpine region, Remote Sens. Environ., 114, 24852499, doi:10.1016/j.rse.2010.05.024, 2010. 
Ferrero, L., Perrone, M. G., Petraccone, S., Sangiorgi, G., Ferrini, B. S., Lo Porto, C., Lazzati, Z., Cocchi, D., Bruno, F., Greco, F., Riccio, A., and Bolzacchini, E.: Vertically-resolved particle size distribution within and above the mixing layer over the Milan metropolitan area, Atmos. Chem. Phys., 10, 3915-3932, doi:10.5194/acp-10-3915-2010, 2010.

Ferrero, L., Mocnik, G., Ferrini, B. S., Perrone, M. G., Sangiorgi, G., and Bolzacchini, E.: Vertical profiles of aerosol absorption coefficient from micro-Aethalometer data and Mie calculation over Milan, Sci. Total Environ., 409, 2824-37, doi:10.1016/j.scitotenv.2011.04.022, 2011a.

Ferrero, L., Riccio, A., Perrone, M. G., Sangiorgi, G., Ferrini, B. S., and Bolzacchini, E.: Mixing height determination by tethered balloon-based particle soundings and modeling simulations, Atmos. Res, 102, 145-156, doi:10.1016/j.atmosres.2011.06.016, $2011 b$.

Ferrero, L., Cappelletti, D., Moroni, B., Sangiorgi, G., Perrone, M. G., Crocchianti, S., and Bolzacchini, E.: Wintertime aerosol dynamics and chemical composition across the mixing layer over basin valleys, Atmos. Environ., 56, 143-153, doi:10.1016/j.atmosenv.2012.03.071, 2012.

Ferrero, L., Sangiorgi, G., Ferrini, B. S., Perrone, M. G., Moscatelli, M., D’Angelo, L., Rovelli, G., Ariatta, A., Truccolo, R., and Bolzacchini, E.: Aerosol corrosion prevention and energy-saving strategies in the design of green data centers, Environ. Sci. Technol., 47, 3856-3864, doi:10.1021/es304790f, 2013.

Ferrero, L., D’Angelo, L., Rovelli, G., Sangiorgi, G., Perrone, M. G., Moscatelli, M., Casati, M., and Bolzacchini, E.: Determination of aerosol deliquescence and crystallization relative humidity for energy saving in free-cooled data centers, Int. J. Environ. Sci. Te., submitted, 2014.

Fierz-Schmidhauser, R., Zieger, P., Gysel, M., Kammermann, L., DeCarlo, P. F., Baltensperger, U., and Weingartner, E.: Measured and predicted aerosol light scattering enhancement factors at the high alpine site Jungfraujoch, Atmos. Chem. Phys., 10, 23192333, doi:10.5194/acp-10-2319-2010, 2010.

Guyon, P., Boucher, O., Graham, B., Beck, J., Mayol-Bracero, O. L., Roberts, G. C., Maenhaut, W., Artaxo, P., and Andreae, M. O.: Refractive index of aerosol particles over the Amazon tropical forest during LBA-EUSTACH 1999, J. Aerosol Sci., 34, 883907, doi:10.1016/S0021-8502(03)00052-1, 2003.

Heald, C. L., Ridley, D. A., Kroll, J. H., Barrett, S. R. H., CadyPereira, K. E., Alvarado, M. J., and Holmes, C. D.: Contrasting the direct radiative effect and direct radiative forcing of aerosols, Atmos. Chem. Phys., 14, 5513-5527, doi:10.5194/acp-14-55132014, 2014.

Heller, W.: Remarks on Refractive Index Mixture Rules, J. Phys. Chem., 69, 1123-1129, 1965.

Heim, M., Mullins, B. J., Umhauer, H., and Kasper, G.: Performance evaluation of three optical particle counters with an efficient "multimodal" calibration method, J. Aerosol Sci., 39, 1019-1031, doi:10.1016/j.jaerosci.2008.07.006, 2008.

Hess, M., Koepke, P., and Schult, I.: Optical Properties of Aerosols and Clouds: The Software Package OPAC, B. Am. Meteorol. Soc., 79, 831-844, doi:10.1175/15200477(1998)079<0831:OPOAAC>2.0.CO;2, 1998.

Heyder, J. and Gebhart, J.: Optimization of response functions of light scattering instruments for size evaluation of aerosol particles, Appl. Optics, 18, 705-711, 1979.
Howell, S. G., Clarke, A. D., Shinozuka, Y., Kapustin, V., McNaughton, C. S., and Huebert, B. J.: Influence of relative humidity upon pollution and dust during ACE-Asia: Size distributions and implications for optical properties, J. Geophys. Res., 111, D06205, doi:10.1029/2004JD005759, 2006.

Hueglin, C., Gehrig, R., Baltensperger, U., Gysel, M., Monn, C., and Vonmont, H.: Chemical characterisation of $\mathrm{PM}_{2.5}$, $\mathrm{PM}_{10}$ and coarse particles at urban, near-city and rural sites in Switzerland, Atmos. Environ., 39, 637-651, doi:10.1016/j.atmosenv.2004.10.027, 2005.

IPCC: Climate Change 2013: The Physical Science Basis. Cambridge University Press, Cambridge, United Kingdom and New York, USA, 2013.

Jacobson, M. Z.: Strong radiative heating due to the mixing state of black carbon in atmospheric aerosols, Nature, 409, 695-697, doi:10.1038/35055518, 2001.

Kato, S., Ackerman, T. P., Mather, J. H., and Clothiaux, E. E.: The $k$ distribution method and correlated-k approximation for a shortwave radiative transfer model, J. Quant. Spectrosc. Ra., 62, 109121, 1999.

Kaufman, Y. J., Tanré, D., and Boucher, O.: A satellite view of aerosols in the climate system, Nature, 419, 215-223, 2002.

Kedia, S., Ramachandran, S., Kumar, A., and Sarin, M. M.: Spatiotemporal gradients in aerosol radiative forcing and heating rate over Bay of Bengal and Arabian Sea derived on the basis of optical, physical, and chemical properties, J. Geophys. Res., 115, D07205, doi:10.1029/2009JD013136, 2010.

Koren, I., Kaufman, Y. J., Remer, L. A., and Martins, J. V.: Measurments of the effect of amazon smoke on inhibition of cloud formation, Science, 303, 1342-1345, 2004.

Koren, I., Martins, J. V., Remer, L. A., and Afargan, H.: Smoke invigoration versus inhibition of clouds over the amazon, Science, 321, 946-949, 2008.

Lesins, G., Chylek, P., and Lohmann, U.: A study of internal and external mixing scenarios and its effect on aerosol optical properties and direct radiative forcing, J. Geophy. Res., 107, AAC5.1AAC5.12, doi:10.1029/2001JD000973, 2002.

Liu, Y. and Daum, P. H.: Relationship of refractive index to mass density and self-consistency of mixing rules for multicomponent mixtures like ambient aerosols, J. Aerosol Sci., 39, 974-986, doi:10.1016/j.jaerosci.2008.06.006, 2008.

Ma, X., Lu, J. Q., Brock, R. S., Jacobs, K. M., Yang, P., and Hu, X.-H.: Determination of complex refractive index of polystyrene microspheres from 370 to $1610 \mathrm{~nm}$, Phys. Med. Biol., 48, 41654172, 2003.

Maletto, A., McKendry, I. G., and Strawbridge, K. B.: Profiles of particulate matter size distributions using a balloonborne lightweight aerosol spectrometer in the planetary boundary layer, Atmos. Environ., 37, 661-670, doi:10.1016/S13522310(02)00860-9, 2003.

Martin, S. T.: Phase Transitions of Aqueous Atmospheric Particles, Chem. Rev., 100, 3403-3454, 2000.

Mayer, B. and Kylling, A.: Technical note: The libRadtran software package for radiative transfer calculations - description and examples of use, Atmos. Chem. Phys., 5, 1855-1877, doi:10.5194/acp-5-1855-2005, 2005.

McMeeking, G. R., Hamburger, T., Liu, D., Flynn, M., Morgan, W. T., Northway, M., Highwood, E. J., Krejci, R., Allan, J. D., Minikin, A., and Coe, H.: Black carbon measurements in the 
boundary layer over western and northern Europe, Atmos. Chem. Phys., 10, 9393-9414, doi:10.5194/acp-10-9393-2010, 2010.

McMeeking, G. R., Morgan, W. T., Flynn, M., Highwood, E. J., Turnbull, K., Haywood, J., and Coe, H.: Black carbon aerosol mixing state, organic aerosols and aerosol optical properties over the United Kingdom, Atmos. Chem. Phys., 11, 9037-9052, doi:10.5194/acp-11-9037-2011, 2011

Morgan, W. T., Allan, J. D., Bower, K. N., Capes, G., Crosier, J., Williams, P. I., and Coe, H.: Vertical distribution of sub-micron aerosol chemical composition from North-Western Europe and the North-East Atlantic, Atmos. Chem. Phys., 9, 5389-5401, doi:10.5194/acp-9-5389-2009, 2009.

Morgan, W. T., Allan, J. D., Bower, K. N., Highwood, E. J., Liu, D., McMeeking, G. R., Northway, M. J., Williams, P. I., Krejci, R., and Coe, H.: Airborne measurements of the spatial distribution of aerosol chemical composition across Europe and evolution of the organic fraction, Atmos. Chem. Phys., 10, 4065-4083, doi:10.5194/acp-10-4065-2010, 2010.

Moroni, B., Cappelletti, D., Marmottini, F., Scardazza, F., Ferrero, L., and Bolzacchini, E.: Integrated single particle-bulk chemical approach for the characterization of local and long range sources of particulate pollutants, Atmos. Environ., 50, 267-277, doi:10.1016/j.atmosenv.2011.12.022, 2012.

Moroni, B., Ferrero, L., Crocchianti, S., Perrone, M. G., Sangiorgi, G., Bolzacchini, E., and Cappelletti, D.: Aerosol dynamics upon Terni basin (Central Italy): results of integrated vertical profile measurements and electron microscopy analyses, Rend. Lincei, 24, 319-328, doi:10.1007/s12210-013-0230-8, 2013.

Pathak, R.: Characteristics of aerosol acidity in Hong Kong, Atmos. Environ., 38, 2965-2974, doi:10.1016/j.atmosenv.2004.02.044, 2004.

Perrone, M. G., Gualtieri, M., Ferrero, L., Lo Porto, C., Udisti, R., Bolzacchini, E., and Camatini, M.: Seasonal variations in chemical composition and in vitro biological effects of fine PM from Milan., Chemosphere, 78, 1368-77, doi:10.1016/j.chemosphere.2009.12.071, 2010.

Perrone, M. G., Larsen, B. R., Ferrero, L., Sangiorgi, G., De Gennaro, G., Udisti, R., Zangrando, R., Gambaro, A., and Bolzacchini, E.: Sources of high PM2.5 concentrations in Milan, Northern Italy: molecular marker data and CMB modelling, Sci. Total Environ., 414, 343-55, doi:10.1016/j.scitotenv.2011.11.026, 2012.

Perrone, M. G., Gualtieri, M., Consonni, V., Ferrero, L., Sangiorgi, G., Longhin, E., Ballabio, D., Bolzacchini, E., and Camatini, M.: Particle size, chemical composition, seasons of the year and urban, rural or remote site origins as determinants of biological effects of particulate matter on pulmonary cells, Environ. Pollut., 176, 215-227, doi:10.1016/j.envpol.2013.01.012, 2013.

Perrone, M. R. and Bergamo, A.: Direct radiative forcing during Sahara dust intrusions at a site in the Central Mediterranean: Anthropogenic particle contribution, Atmos. Res, 101, 783-798, doi:10.1016/j.atmosres.2011.05.011, 2011.

Pesava, P., Horvath, H., and Kasahara, M.: A local optical closure experiment in Vienna, J. Aerosol Sci., 32, 1249-1267, doi:10.1016/S0021-8502(01)00053-2, 2001.

Potukuchi, S. and Wexler, A.: Identifying solid-aqueous-phase transitions in atmospheric aerosols. II. Acidic solutions, Atmos. Environ., 29, 3357-3364, 1995.
Ramana, M. V., Ramanathan, V., Kim, D., Roberts, G. C., and Corrigan, C. E.: Albedo, atmospheric solar absorption and heating rate measurements with stacked UAVs, Q. J. Roy. Meteorol. Soc., 133, 1913-1931, doi:10.1002/qj.172, 2007.

Ramana, M. V., Ramanathan, V., Feng, Y., Yoon, S.-C., Kim, S.-W., Carmichael, G. R., and Schauer, J. J.: Warming influenced by the ratio of black carbon to sulphate and the black-carbon source, Nat. Geosci., 3, 542-545, doi:10.1038/ngeo918, 2010.

Ramanathan, V. and Carmichael, G.: Global and regional climate changes due to black carbon, Nat. Geosci., 1, 221-227, 2008.

Ramanathan, V. and Feng, Y.: Air pollution, greenhouse gases and climate change: Global and regional perspectives, Atmos. Environ., 43, 37-50, doi:10.1016/j.atmosenv.2008.09.063, 2009.

Randriamiarisoa, H., Chazette, P., Couvert, P., Sanak, J., and Mégie, G.: Relative humidity impact on aerosol parameters in a Paris suburban area, Atmos. Chem. Phys., 6, 1389-1407, doi:10.5194/acp-6-1389-2006, 2006.

Raut, J.-C. and Chazette, P.: Vertical profiles of urban aerosol complex refractive index in the frame of ESQUIF airborne measurements, Atmos. Chem. Phys., 8, 901-919, doi:10.5194/acp-8-9012008, 2008.

Rees, S. L., Robinson, A. L., Khlystov, A., Stanier, C. O., and Pandis, S. N.: Mass balance closure and the Federal Reference Method for PM2.5 in Pittsburgh, Pennsylvania, Atmos. Environ., 38, 3305-3318, doi:10.1016/j.atmosenv.2004.03.016, 2004.

Rodríguez, S., Van Dingenen, R., Putaud, J.-P., Dell'Acqua, A., Pey, J., Querol, X., Alastuey, A., Chenery, S., Ho, K.-F., Harrison, R., Tardivo, R., Scarnato, B., and Gemelli, V.: A study on the relationship between mass concentrations, chemistry and number size distribution of urban fine aerosols in Milan, Barcelona and London, Atmos. Chem. Phys., 7, 2217-2232, doi:10.5194/acp-72217-2007, 2007.

Roessler, D. M.: Photoacoustic insight on diesel exhaust particles, Appl. Optics, 23, 1148-1155, 1984.

Safai, P. D., Raju, M. P., Maheshkumar, R. S., Kulkarni, J. R., Rao, P. S. P., and Devara, P. C. S.: Vertical profiles of black carbon aerosols over the urban locations in South India, Sci. Total Environ., 431, 323-331, doi:10.1016/j.scitotenv.2012.05.058, 2012.

Saha, A., Mallet, M., Roger, J. C., Dubuisson, P., Piazzola, J., and Despiau, S.: One year measurements of aerosol optical properties over an urban coastal site: Effect on local direct radiative forcing, Atmos. Res., 90, 195-202, doi:10.1016/j.atmosres.2008.02.003, 2008.

Samset, B. H., Myhre, G., Schulz, M., Balkanski, Y., Bauer, S., Berntsen, T. K., Bian, H., Bellouin, N., Diehl, T., Easter, R. C., Ghan, S. J., Iversen, T., Kinne, S., Kirkevåg, A., Lamarque, J.F., Lin, G., Liu, X., Penner, J. E., Seland, Ø., Skeie, R. B., Stier, P., Takemura, T., Tsigaridis, K., and Zhang, K.: Black carbon vertical profiles strongly affect its radiative forcing uncertainty, Atmos. Chem. Phys., 13, 2423-2434, doi:10.5194/acp-13-24232013, 2013.

Sangiorgi, G., Ferrero, L., Perrone, M. G., Bolzacchini, E., Duane, M., and Larsen, B. R.: Vertical distribution of hydrocarbons in the low troposphere below and above the mixing height?: Tethered balloon measurements in Milan, Italy, Environ. Pollut., 159, 3545-3552, doi:10.1016/j.envpol.2011.08.012, 2011.

Seinfeld, J. H. and Pandis, S. N.: Atmos. Chem. Phys. - From air pollution to climate change. Wiley-Interscience edition, 1998. 
Schmid, O., Artaxo, P., Arnott, W. P., Chand, D., Gatti, L. V., Frank, G. P., Hoffer, A., Schnaiter, M., and Andreae, M. O.: Spectral light absorption by ambient aerosols influenced by biomass burning in the Amazon Basin. I: Comparison and field calibration of absorption measurement techniques, Atmos. Chem. Phys., 6, 3443-3462, doi:10.5194/acp-6-3443-2006, 2006.

Schneider, J., Hings, S. S., Nele Hock, B., Weimer, S., Borrmann, S., Fiebig, M., Petzold, A., Busen, R., and Kärcher, B.: Aircraftbased operation of an aerosol mass spectrometer: Measurements of tropospheric aerosol composition, J. Aerosol Sci., 37, 839857, doi:10.1016/j.jaerosci.2005.07.002, 2006.

Schumann, T.: On the use of a modified clean-room optical particle counter for atmosperic aerosols at high relative humidity, Atmos. Res, 25, 499-520, doi:10.1016/0169-8095(90)90035-B, 1990.

Schuster, G. L., Dubovik, O., Holben, B. N., and Clothiaux, E. E.: Inferring black carbon content and specific absorption from Aerosol Robotic Network (AERONET) aerosol retrievals, J. Geophys. Res., 110, D10S17, doi:10.1029/2004JD004548, 2005.

Schwarz, J. P., Gao, R. S., Fahey, D. W., Thomson, D. S., Watts, L. A., Wilson, J. C., Reeves, J. M., Darbeheshti, M., Baumgardner, D. G., Kok, G. L., Chung, S. H., Schulz, M., Hendricks, J., Lauer, A., Kärcher, B., Slowik, J. G., Rosenlof, K. H., Thompson, T. L., Langford, A. O., Loewenstein, M., and Aikin, K. C.: Single-particle measurements of midlatitude black carbon and light-scattering aerosols from the boundary layer to the lower stratosphere, J. Geophys. Res., 111, D16207, doi:10.1029/2006JD007076, 2006.

Schwarz, J. P., Spackman, J. R., Gao, R. S., Watts, L. A., Stier, P., Schulz, Davis, S. M., Wofsy, S. C., and Fahey, D. W.: Globalscale black carbon profiles observed in the remote atmosphere and compared to models, Geophys. Res. Lett., 37, L18812, doi:10.1029/2010GL044372, 2010.

Schwarz, J. P., Samset, B. H., Perring, A. E., Spackman, J. R., Gao, R. S., Stier, P., Schulz, M., Moore, F. L., Ray, E. A., and Fahey, D. W.: Global-scale seasonally resolved black carbon vertical profiles over the Pacific, Geophys. Res. Lett., 40, 1-6, doi:10.1002/2013GL057775, 2013.
Stamnes, K., Tsay, S., Wiscombe, W., and Jayaweera, K.: A numerically stable algorithm for discrete-ordinate-method radiative transfer in multiple scattering and emitting layered media, Appl. Optics, 27, 2502-2509, 1988.

Stier, P., Seinfeld, J. H., Kinne, S., and Boucher, O.: Aerosol absorption and radiative forcing, Atmos. Chem. Phys., 7, 5237-5261, doi:10.5194/acp-7-5237-2007, 2007.

Subramanian, R., Donahue, N. M., Bernardo-Bricker, A., Rogge, W. F., and Robinson, A. L.: Insights into the primary-secondary and regional-local contributions to organic aerosol and $\mathrm{PM}_{2.5}$ mass in Pittsburgh, Pennsylvania, Atmos. Environ., 41, 74147433, doi:10.1016/j.atmosenv.2007.05.058, 2007.

Tripathi, S. N., Srivastava, A. K., Dey, S., Satheesh, S. K., and Krishnamoorthy, K.: The vertical profile of atmospheric heating rate of black carbon aerosols at Kanpur in northern India, Atmos. Environ., 41, 6909-6915, 2007.

Trompetter, W. J., Grange, S. K., Davy, P. K., and Ancelet, T.: Vertical and temporal variations of black carbon in New Zealand urban areas during winter, Atmos. Environ., 75, 179187, doi:10.1016/j.atmosenv.2013.04.036, 2013.

Weingartner, E., Saathoff, H., Schnaiter, M., Streit, N., Bitnar, B., and Baltensperger, U.: Absorption of light by soot particles: determination of the absorption coefficient by means of aethalometers, J. Aerosol Sci., 34, 1445-1463, doi:10.1016/S00218502(03)00359-8, 2003.

Zarzycki, C. M. and Bond, T. C.: How much can the vertical distribution of black carbon affect its global direct radiative forcing?, Geophys. Res. Lett., 37, L20807, doi:10.1029/2010GL044555, 2010.

Zhang, Y., Seigneur, C., Seinfeld, J. H., Jacobson, M., Clegg, S. L., and Binkowski, F. S.: A comparative review of inorganic aerosol thermodynamic equilibrium modules: similarities, differences, and their likely causes, Atmos. Environ., 34, 117-137, 2000. 